\title{
Two Faces of Decomposability in Search: Evidence from the Recorded Music Industry 1995-2015*
}

\author{
Sungyong Chang \\ London Business School \\ schang@london.edu
}

January 29, 2022

\begin{abstract}
We propose that decomposability may generate a trade-off across different stages of search. We compare (1) a decomposed search - the process of searching by producing a decomposed module, and (2) an integrated search - the process of searching by producing a full-scale product. In the variation generation stage, decomposability can allow firms to simultaneously experiment with more alternatives than an integrated search. However, in the selection and retention stages, a decomposed search may be more vulnerable to imperfect evaluation (i.e., noise) than an integrated search because a larger number of promising alternatives could be missed after the initial evaluation. The rationale behind this statement is that (1) more alternatives will face an unlucky draw in their initial evaluation, and (2) a decomposed search results in a higher performance target for giving a second production chance than that of an integrated search. We test our theory with a unique empirical setting, the recorded music industry, where singles (i.e., decomposed products) and albums (i.e., integrated products) have coexisted since the early twentieth century. In the variation generation stage, single-producing firms experiment with $35.22 \%$ more new artists than album-only-producing firms. In the selection and retention stage, single-producing firms are $58.89 \%$ more likely to neglect top-tier artists who failed in their first releases. Approximately $80 \%$ of the increase in neglecting top-tier artists came from the increases in the number of new artists experimented with (because of single production), and the other $20 \%$ of the increase came from a higher performance target.
\end{abstract}

Keywords: Decomposability, Evolutionary Perspective on Search, Behavioral Theory of the Firm, Alternative Evaluation

*Acknowledgement: I am grateful to Bruce Kogut, Stephan Meier, Evan Rawley, Vanessa Burbano, Bo Cowill, Sendil Ethiraj, Donal Crilly, Olenka Kacperczyk, Christina Fang, Richard R. Nelson, Damon Phillips, Kylie Jiwon Hwang, Jenna Song, Daniel Keum, Hyunseob Kim, and seminar participants at Bocconi University, Boston University, Columbia Business School, Harvard Business School, HEC Paris, HKUST, KAIST, INSEAD, London Business School, New York University, Ohio State University, University of Connecticut, University of Minnesota, University of North Carolina Chapel Hill, University of Surrey, University of Wisconsin-Madison, University of Washington for helpful comments and suggestions. I gratefully acknowledge funding support from the Jerome A. Chazen Institute for Global Business, Center for Japanese Economy and Business, and Sanford Bernstein \& Co. Center for Leadership and Ethics at Columbia Business School. 


\section{Introduction}

Simon's (1962) work on the architecture of complexity provides building blocks for analyzing how the properties of complex systems affect the discovery of promising alternatives (e.g., resources, technologies, or products). He emphasizes that one of the fundamental features of complex systems is decomposability, the fact that patterns of interactions among elements of a complex system are not diffuse but tend to be tightly clustered into nearly isolated subsets of interactions (i.e., modules). Subsequent theoretical studies have shown that decomposability helps firms discover a promising option by facilitating module-level experimentations (i.e., producing more variations) (Kogut and Bowman, 1995, Baldwin and Clark, 2000, Marengo, Dosi, Legrenzi, \& Pasquali, 2000, Ethiraj and Levinthal, 2004, Fang and Kim, 2018). As Knudsen and Levinthal (2007) note, a critical facet has been largely underexplored in this tradition, namely, how firms select and retain the promising ones among experimented options. To advance our understanding of this topic, we explore the roles of decomposability in the discovery of new promising alternatives in the different stages of the search. We argue that decomposability may facilitate experimentation in the variation generation stage but can decrease the efficacy of selection and retention.

The evolutionary perspective on search (e.g., Simon 1955, Zollo and Winter, 2002, Knudsen and Levinthal, 2007) provides useful insights into how decomposability can create a trade-off across different stages of the discovery of new alternatives. First, some possible alternatives are experimented on in the variation generation stage. The realization from these draws is then evaluated, and some of the highly evaluated alternatives will be selected and retained. Across the different stages, we compare the two modes of search: (1) the case in which firms experiment with and evaluate an alternative by producing a full-scale product (i.e., integrated search) and (2) the case in which firms experiment with and evaluate an alternative by producing a decomposed module (i.e., decomposed search). For example, in the music industry, firms can experiment with a new artist and evaluate his or her talent by producing either an album (i.e., release of multiple songs - a full-scale, integrated product) or a single (i.e., release of a single song - a decomposed module). Integrated search has been the base mode of search in many real-world settings. For example, for the past two decades, a large number of music companies (about $60.7 \%$ of companies in the world) produced only albums, 
but other companies produced singles. ${ }^{1}$

First, we argue that a decomposed search may be beneficial during the variation generation stage. March and Simon (1958) note that as choice sets are not available ex-ante to firms but must be constructed, experimenting with new alternatives is the first step of a search. We emphasize that decomposability not only lowers the cost of generating an alternative but also enables parallel experimentations (Marengo et al., 2000, Ethiraj and Levinthal, 2004) because a decomposed search helps managers focus on a subset (i.e., a smaller number of attributes) of the whole search space (i.e., all possible attributes). If firms experiment with more new alternatives, firms will benefit because it increases the chance of discovering promising alternatives with higher upside potentials.

However, the gains from a decomposed search may hurt the discovery of promising alternatives in the selection and retention stage. Knudsen and Levinthal (2007) note that the evaluation of alternatives is likely to be imperfect. A promising option that faces an unlucky failure in the initial evaluation may be mistakenly considered unpromising by firms and lose future chances in these firms. Under the condition of noise in evaluation (e.g., Caves, 2000, Knudsen and Levinthal, 2007, Fang, Kim, Miliken, 2014), it is challenging for firms to infer an alternative's true quality from a one-shot experimentation result. As Simon (1955) notes, if the evaluated performance of an alternative satisfies a performance target (i.e., a minimum performance criterion), the firm will select and retain the option for future use. Otherwise, firms will search for other alternatives. We argue that when firms implement a decomposed search, each alternative will more likely be missed out on after its initial evaluation than when firms implement an integrated search for the following two reasons.

First, when firms implement a decomposed search, they will experiment simultaneously with more new alternatives than when implementing only an integrated search. In the presence of noise, as firms experiment with more alternatives, more alternatives will face an unlucky draw in their initial evaluation. Promising alternatives are not exceptions to this tendency; some will also face an unlucky draw and be evaluated as unpromising despite their underlying quality. Second, we argue that a decomposed search may increase the performance target because implementing a decom-

\footnotetext{
${ }^{1}$ Among single-producing music companies, $61.5 \%$ companies produced singles and albums and $38.5 \%$ companies produced only singles.
} 
posed search increases the number of outside options that firms can experiment with, resulting in a higher expected quality of the best option among these outside options. The higher performance target may lead to early termination of the investment in each alternative. Thus, if firms implement a decomposed search, they are more likely to make omission errors when giving a second chance to a promising option.

We demonstrate the dual roles of decomposability in search with the recorded music industry where (1) artists' talent (i.e., each artist is an alternative in our setting) is the most important source of creativity and profit and (2) decomposed products (i.e., singles) and integrated products (i.e., albums) have coexisted since the early 20th century. In particular, we compare (1) music labels that only produced integrated products (i.e., album-only producing firms) with (2) music labels that produced decomposed products (i.e., single-producing firms). We collect and match multiple databases: MusicBrainz, AcousticBrainz, Spotify APIs, and Discogs. The sample covers 114,488 artists, 1,026,309 songs, and 9,667 music firms in 29 countries from 1995 to 2015. The results from OLS models, instrumental variable estimators, and matching estimators support our prediction. First, single-producing firms experiment with $35.22 \%$ more new artists, some of whom may turn out to be talented artists. However, single-producing firms are $58.89 \%$ more likely to miss out on top-tier artists who experience failure with their first releases. Approximately $80 \%$ of the increase in neglecting top-tier artists came from the increases in the number of new artists experimented, and the other $20 \%$ of the increase came from a higher performance target.

This study contributes to the core tenets of the behavioral theory of the firm. Our theory and findings have useful implications regarding the roles of decomposability in search by bridging the three strands of the behavioral theory of the firm: (1) the literature on the architecture of complexity (e.g., Simon, 1962, Baldwin and Clark, 2000, Ethiraj et al., 2008), (2) the literature on performance targets and aspirations, and (3) the literature on the role of imperfect evaluation and noise (e.g., Cyert and March, 1963, Knudsen and Levinthal, 2007, Fang, Kim, Miliken, 2014).

First, starting with the work of Nelson (1961), strategy scholars have examined the role of parallel experimentations in the discovery of new solutions (e.g., Eggers, 2012, Eggers and Green, 2012, Posen, Matignoni, Levinthal, 2012). Our theory highlights that decomposability has not 
been explored as a characterization of parallel experimentation with new alternatives such as new resources, technologies, assets, or workers. Specifically, this study contributes to the burgeoning empirical literature on decomposability and complexity (e.g., Zhou, 2011, Ganco, 2013, Piazzai and Wijnberg, 2019, Ethiraj and Zhou, 2019). As Baumann, Schmidt, and Stieglitz (2019) note, to date, the theoretical work has been only incidentally complemented by empirical research, and the theoretical and empirical studies remain rather disconnected. We attempt to tighten the link between theoretical and empirical work by analyzing an unusual setting to measure decomposability and its role in discovering new promising alternatives.

Second, this study speaks to the literature on performance target and aspiration level (e.g., Cyert and March, 1963, Greve, 2003). Changes in search behavior in response to performance lower than the performance target have been active research topics (Greve and Gaba, 2017). Firm behavior is guided by the discrepancy between the performance target and actual performance (e.g., Bromiley, 1991, Keum and Eggers, 2018). Although numerous papers exist on the consequences of financial performance aspirations (e.g., ROS, ROA, or ROE), less attention has been paid to how organizational performance targets are determined. In particular, little empirical research has been done on this topic. As Shinkle (2012) notes, "the literature lacks robust empirical evidence on the antecedents of aspirations[performance targets]. Most studies rely on the formal theoretical model of behavioral theory to infer aspiration levels[performance targets]." Our study provides empirical evidence as well as a theoretical argument that decomposability plays an important role in shaping the performance target.

Third, this study advances our understanding of the ramifications of imperfect evaluation in complex problem-solving. As Zollo and Winter (2002) note, a search is primarily carried out through efforts aimed at generating the necessary range of new options as well as selecting the most appropriate ones. In selecting appropriate options, while prior studies have examined heterogeneity in forecasting ability and its origin (e.g., Makadok and Walker, 2000, Adner and Helfat, 2003, Denrell and Fang, 2010), our study views a decomposed search as a heuristic to complement forecasting abilities. Theoretically, we pinpoint a hidden drawback of decomposed search (i.e., the omission error in giving a second chance to the existing option) in search. 


\section{Theory and Hypotheses}

Studies on the behavioral theory of the firm have long recognized the multi-phased nature of the innovation process (e.g., Zollo and Winter, 2002, Knudsen and Levinthal, 2007). This process starts with a search for new options (i.e., variation generation), followed by an evaluation of those new options, then concludes with selection and retention (e.g., Keum and See, 2019). This perspective on search provides important insights into how decomposability can create trade-offs across different phases of the innovation process.

\subsection{Decomposability in the variation generation stage}

Since Simon (1955) characterized much of the discovery process as a sequential search process, management scholars have explored the problem that arises with the discovery of new alternatives. The optimal solution to the discovery problem draws on the "bandit" literature (e.g., Kogut and Kulatilaka, 1994, Denrell and March, 2001, Posen and Levinthal, 2012, Lee and Puranam, 2016). This tradition describes experimentation as a trial-and-error process (e.g., Kulkarni and Simon, 1990, Thomke, von Hippel, and Franke, 1998). Through experimentation, firms can reveal information about new alternatives; if one or more new options outperform existing options, the new ones will replace the old. Leiponen and Helfat (2010) note that the likelihood of obtaining a favorable draw from a distribution of payoffs increases as the number of draws increases. Therefore, the benefits of experimentation are derived from information on whether new choices have upside potential.

An integrated search incurs a higher cost of experimenting with new alternatives because an integrated search requires developing a full-blown product with more elements. In particular, a full-blown product increases inputs, such as resources and time for design and development (Ethiraj and Levinthal, 2004). A full-blown product is also more complex to produce than a module (Baldwin and Clark, 2000). In reality, many firms implement only integrated search. For example, in the music industry, for a long time (especially in the 1980s and 1990s), many music labels produced only albums (i.e., integrated search); when these album-only-producing firms experiment with a new artist (i.e., a new-to-the-world artist) by producing an album, which is a costly option. 
The high cost of experimentation limits the number of alternatives that firms can experiment with (Baldwin and Clark, 2000, Loch, Terwiesch, and Thomke, 2001). Because of this limitation, firms that implement only integrated search will be less likely to simultaneously engage in multiple alternatives.

Compared with the integrated only search, firms that implement a decomposed search can experiment with more options than when they implement only integrated search in the variation generation stage. First, a decomposed search significantly reduces the costs of experimenting with new alternatives because experimenting with a partial product (e.g., a module) generates useful information on the potential of an alternative (Baldwin and Clark, 2000, Ethiraj and Levinthal, 2004). By enforcing decomposition, it is possible to test an alternative without producing the whole system. The low cost of experimentation allows firms to experiment with more new options. Decomposition slashes the cost to free up experimentation capacity as well as make possible what-if experiments that, in the past, have been either prohibitively expensive or nearly impossible to carry out. In contrast, the high cost of experimentation has long dampened companies' attempts to test a new alternative (Thomke, 2003). Empirical research has demonstrated that the low cost of experimentation facilitates testing with more new products, technologies, or start-ups for which the outcome of success follows a highly skewed distribution. For example, Ewens, Nanda, and RhodesKropf (2018) provide evidence that the low cost of experimentation encourages venture capitalists to invest in more new start-ups in an investment strategy called "spray and pray."

Second, a decomposed search offers the advantage of the parallelism of experimentations (Baldwin and Clark, 2000, Marengo et al., 2000, Loch et al., 2001). As Nelson (1961, p. 353) emphasizes, with parallel experimentations, firms can benefit from information acquired by engaging in multiple alternatives simultaneously, rather than sequentially. As alternatives constitute different approaches to solving the same problem, the number of alternatives that a firm would experiment with simultaneously is an important factor in search. Loch et al. (2001) provide computer simulation as an exemplary technology to facilitate less costly and faster experimentations, resulting in a more promising solution concept that could not be tested with costlier and slower technologies.

In sum, decomposition reduces the cost of experimenting with new alternatives and facilitates 
the parallelism of experimentations. Firms that implement both a decomposed and an integrated search will experiment with more options. Therefore, we hypothesize the following:

Hypothesis 1. When firms implement a decomposed search, they will simultaneously experiment with more new alternatives than when firms implement only an integrated search.

\subsection{Decomposability in the selection and retention stages}

We argue that under imperfect evaluation, the gains from a decomposed search in the variation generation stage might encounter a trade-off with a disadvantage in selection and retention stages. Nelson (1961) notes that the problem of choosing among alternatives is a difficult one, and it is easy to make choices which, ex-post, turn out to be the wrong ones in the presence of noise. The behavioral models of selection can be distinguished from the conventional economic models of selection, in part, because the evaluation of searched alternatives is likely to be imperfect (e.g., Knudsen and Levinthal, 2007, Fang, Kim, Miliken, 2014). In the presence of noise, firms may erroneously reject a superior alternative. For example, in our research setting, talented artists who face an unlucky failure from their first releases might mistakenly be considered untalented by firms and lose future production opportunities.

Second, as Simon noted (1955), if the evaluated performance of an option satisfies a minimum performance criterion, the firm will select and retain the option for future use. Otherwise, firms will search for other alternatives. Subsequent literature has christened such minimum criterion as the performance target or aspiration level (e.g., Cyert and March, 1963, Greve, 2003, Audia and Greve 2006, Lant and Shapira, 2008, Gaba and Joseph, 2013). ${ }^{2}$ Here, we focus on a type of omission error in the selection and retention stages: missing out on promising alternatives after the first evaluation of those alternatives. This type of error is especially likely to occur when the alternative faces an unlucky draw in its initial evaluation, and the evaluated performance does not satisfy the performance target. In the presence of noise in performance evaluation, no matter whether firms experiment with a decomposed module or an integrated product, this type of omission error is

\footnotetext{
${ }^{2}$ For studies on the performance target (or aspiration), Shinkle (2012), Greve and Gaba (2017) provide comprehensive reviews for this topic.
} 
inevitable. We argue that when firms implement a decomposed search, more alternatives could be missed out on after its first evaluation than when firms implement an integrated search, for the following two reasons.

The first reason is rather straightforward. As we derive in Hypothesis 1, when firms implement a decomposed search, they will experiment simultaneously with more new alternatives than when they implement only an integrated search. In the presence of noise, as firms experiment with more alternatives, more alternatives will face an unlucky draw in their first evaluation. Promising alternatives are not exceptions to this tendency; some will also face an unlucky draw and be evaluated as unpromising despite their underlying quality. Therefore, the observed performance of more alternatives in the first evaluation will fall below the performance target, and these alternatives will not be selected for future use.

Second, we argue that a decomposed search may increase the performance target necessary for being selected and retained, resulting in a higher chance of missing out on promising alternatives that were evaluated as unpromising ones in their initial evaluations (i.e., not giving a second evaluation chance to a promising alternative). In the presence of noise, if the performance target becomes higher, firms will be more likely to miss out on promising alternatives after the first evaluation. Why could a decomposed search lead to a higher performance target? We argue that the formation of the performance target relies on the expected quality of the best option among these outside options. As we explained in deriving the first hypothesis, a decomposed search increases the number of new alternatives that firms can experiment with. The distribution of outcomes in many settings, such as the discovery of talent, new technologies, start-up ideas, and new business opportunities, tends to be highly skewed (Nelson and Winter 1978, Ewens et al., 2018). Under such a skewed distribution, the expected quality of the most promising option that firms can discover will matter. If the number of options that firms can experiment with increases, the expected quality of the most promising option will increase. More formally, for a random variable $x_{i}$ from any distribution, the expected quality of the most prominent option of the firm is $E\left(\max \left(x_{1}, x_{2}, \ldots x_{k}\right)\right)$ when the number of new options that the firm can experiment with is $k$. When $k<n, E\left(\max \left(x_{1}, x_{2}, \ldots x_{k}\right)\right)$ is smaller than $E\left(\max \left(x_{1}, x_{2}, \ldots x_{n}\right)\right)$. Therefore, more options will lead to a higher expected quality of the most 
prominent outside option.

Although two alternatives show the same evaluated performance in their initial evaluation, if firms implement a decomposed search, they are less likely to give a second evaluation chance than firms that implement only an integrated search. Figure 1 visualizes this mechanism by comparing a decomposed search and an integrated search. In Figure 1, the true quality of an alternative is 5 , and the evaluated performance is a random draw from the normal distribution, $N(5,1)$. Let us assume that 5 is high enough to be a promising alternative. A decomposed search has a higher performance target (i.e., a higher expected quality of the most promising outside option); for ex-

ample, in Panel A, the performance target of the decomposed search is 4, and the chance of missing out on promising options with the quality five will be $15.85 \%$. However, in Panel B, an integrated search has a lower performance target (i.e., a lower expected quality of the most promising outside option). As the performance target is 3 , the chance of missing out on promising options with the quality level 5 will be $2.27 \%$, which is lower than that of a decomposed search.

-Insert Figure 1 about here-

Taken together, under imperfect evaluation, a decomposed search might increase the chance of missing out on promising alternatives after their first evaluation. Thus, we hypothesize:

Hypothesis 2. When firms implement a decomposed search, they will be more likely to miss out on promising alternatives after its initial evaluation than when firms implement only an integrated search.

\section{Empirical Context: The Recorded Music Industry}

\subsection{The discovery of new artists in the recorded music industry}

Music firms are called record labels or, more simply, labels. In this study, we focus on music production labels that conduct the talent scouting and development of new artists (i.e., a type of alternative), called "artists and repertoire (A\&R)," and that maintain contracts with recording artists or bands. The International Federation of the Phonographic Industry (IFPI, 2015, p. 9) describes music as an investment-intensive business, as the first major activity that music firms have 
traditionally undertaken is the discovery of new artists (i.e., new-to-the-world artists). Indeed, music firms' investment in A\&R and marketing in 2014 totaled more than $\$ 4.3$ billion, which accounts for more than $10 \%$ of global music sales (IFPI, 2015). According to the IFPI, in 2014, the cost to experiment with a new artist was at least $\$ 500,000$ and, on average, $\$ 1$ million. Common features of contracts signed with emerging artists include the payment of advances, recording costs, tour support, video production, and marketing and promotion costs, as shown in Table 1. In comparison with music firms, online music providers, including online music service providers such as Spotify, iTunes, YouTube, or SoundCloud, spend no money on an upfront investment for talent discovery. This phenomenon indicates that music firms remain the largest upfront investors in artists' careers.

\section{-Insert Table 1 about here-}

Many would-be artists seek to make their music available to consumers. These potential music artists differ substantially in both their ex-ante promise (how broadly appealing the artist would be if their work were produced) and their ex-post success in commercialization (how successful they become) (Benner and Waldfogel, 2016). Caves (2003, p.74) emphasized that "nobody knows," which refers to "the fundamental uncertainty that faces the producer of a creative good. All inputs must be incorporated and the good presented to its intended customers before the producer learns their reservation prices." This reason is primarily why this study focuses on commercialization and not the pre-commercialization process as experimentation. Additionally, it is almost impossible to collect data on pre-commercialization experimentations (either artists or songs).

Even artists cannot accurately assess their own talent to achieve commercial success (Caves, 2000, Tervio, 2009). For example, Elvis Presley is one of the most significant cultural icons of the 20th century and is referred to as "the King of Rock and Roll." Guralnick (2012) notes that Elvis did not understand his talent, and he chose Sun Records, a small independent music firm in the 1950s, in the hope of being discovered. After he finished his audition with Sun Records, the CEO, Sam Phillips, and his secretary wrote Elvis' name, and the secretary added her own commentary: "Good ballad singer. Hold." Today, Sun Records is known as the music firm where a music genre, rock and roll, was born because it discovered Elvis Presley. This history evidently shows that it is challenging for firms to evaluate artists' talent ex-ante. 
In addition, even after having a chance to produce and release music, artists may face unlucky commercial results with their first release. The talent of an artist partially determines the odds of the success of their music. After failures with their first releases, many artists experience terminations in their contracts. They are forced to seek new opportunities with other music firms. Our data analysis indicates that, from 1960-2015, only $17 \%$ of artists had a second production chance with the same firm. The other $83 \%$ had to leave their first music firm. Some of the artists who left the first firm became top-notch, talented artists. One of our key informants, from Sony Music Entertainment, introduced Mumford and Sons, a music group that experienced failure with their first release, as an exemplary case in which Sony missed out on talented artists after an initial failure. The group initially signed with Chess Records (a subsidiary of Sony Music Entertainment) and debuted in 2009 with the single "Mumford \& Sons." As executives at Chess Records were disappointed by the commercial outcome of the group's first single, the company did not extend the contract with Mumford and Sons. The group had to leave, but, luckily, they were given a second chance with another company, Island Records, a subsidiary of Universal Music Group. At Island Records, Mumford and Sons made popular songs like "I will wait," and they won a Grammy award in 2014. This case is considered one of Sony Music's biggest mistakes in the 2000s.

\subsection{Singles vs. albums}

A release is a broad term that covers two different forms: singles or albums. Music firms commonly classify a release with a small number of songs as a single and a release with a large number of songs as an album (which has, on average, twelve songs in our sample). If a music firm produces some of its work as a single (i.e., a decomposed product) instead of an album (i.e., an integrated product), the production and marketing cost is smaller. In addition, another key informant from Sony Music Entertainment states that producing albums requires a greater cost and commitment than producing singles: "Albums are much more expensive. More studio time, more writing, more production hours, more involvement of producers, more people's input [are] needed on an album vs. a single. [Albums] also require far more hours in the recording and mixing studios, more hours of mastering. It comes out to [albums being] ... more expensive than singles in terms of music 
production costs."

Many new artists debuted with singles. Elvis Presley made five singles with Sun Records. Another example is the discography of Aqua, a Danish-Norwegian dance-pop band. This band debuted with a single and made singles until they had an international breakthrough with their single, "Barbie Girl," in 1997. More recently, "Cheerleader," a song recorded by Jamaican singer OMI, was released as a single by OUFAH, an independent music firm. The song appeared on the Billboard Hot 100 in the United States in May 2015 and ranked first on 26 countries' music charts.

How do music companies and artists choose between singles versus albums? Passman (2003) notes that artists usually have little say on this part. Music firms tend to have strong bargaining power over artists because these firms play a critical role in producing and commercializing music (Caves, 2000, Passman, 2003). Coyle (2004, pp. 32-33) vividly describes this situation as follows: "Yet what they [artists] lack as individual artists is the enormous marketing muscle it takes [to] turn a great song into a hit." Because of the essential role of music labels and the perennial oversupply of would-be artists, ${ }^{3}$ "record deals are traditionally structured with the company having the smallest obligation that it can negotiate, while keeping the option to get as much product as possible" (Passman, 2003, p. 64). For a regular record deal, a company usually commits to record one release (either a single or an album $)^{4}$ of an artist and has the option to produce an additional four or five releases, each at the company's election. Passman (2003) also notes that most record deals do not require the company to make a release. Additionally, the company usually decides the format of the music release (i.e., a single or an album). As emphasized by Passman (2003, p. 64), "this is not only true for new artists, but also for mid-level and even superstars."

The artistic and commercial importance of the single (as compared to the album) has varied over time and across countries. Britt (1989) notes that "the single enjoyed its peak in the 1960s

\footnotetext{
${ }^{3}$ For a new-to-the-world artist, the chance of being signed with a music company is low. A 2016 recent survey done by ReverbNation and Digital Music News revealed that more than $75 \%$ of (unsigned) artists want to get signed with music firm(s); however, in reality, most artists do not have such fortune (Resnikoff, 2016). Because competition is fierce for getting signed with music labels, the bargaining power of music firms usually dominates the bargaining power of new artists unless these artists have some popularity before signing a deal. A key informant from SM Entertainment, one of the top 3 music firms in South Korea, also underscores that artists tend to have weak bargaining power over music firms (or producers) when deciding on the format or music genres/types of their first and subsequent releases.

${ }^{4} \mathrm{~A}$ standard record deal (i.e., contract) was a typical record deal before the digital revolution; the contract was based on the number of artists' albums to which music companies owned the copyright. A standard record deal is no longer standard after the digital revolution; single deals - based on the number of singles - became industry standard.
} 
[during] the rise of musical phenomena like the British Invasion, Motown, and R\&B." However, starting from the mid-sixties, the album became a greater focus as artists created albums of coherent, themed songs. Bob Dylan's first album, Bob Dylan, is an exemplary case. As a result, singles generally received increasingly less attention in the United States, Japan, and South Korea compared to albums. However, in other countries like the UK, the Netherlands, and Australia, singles survived as a different form of music; singles continued to be produced and sold, and they maintained their popularity in these countries.

In this study, we compare two types of firms: (1) firms producing only albums (i.e., firms implementing only an integrated search) and (2) firms producing singles (i.e., firms implementing a decomposed search; $68.5 \%$ of them produce albums and singles; the other $31.5 \%$ of firms produce only singles). For all countries, before digitization, albums are the main type of releases. Table 2 summarizes the link between our hypotheses and the empirical setting.

-Insert Table 2 about here-

\subsection{Entry of iTunes Music Store}

Firms' decision-making between two different forms (singles vs. albums) was greatly affected by digitization. In particular, digitization shook the music industry in the late 1990s with the MP3 format, introduced in 1993. Many people illegally downloaded songs through file-sharing websites like Napster. Apple opened the iTunes Music Store (hereafter "iTunes"), the first online music store, in 2003 as a way to solve the piracy problem. Steve Jobs succeeded in convincing the five major labels to offer their content through iTunes, which provided a market for songs as well as albums. The impact of iTunes was great, as indicated by the fact that iTunes accounted for $88 \%$ of the US online music market share in the late 2000s. The popularity of singles increased after the introduction of iTunes. This change brought about by iTunes increased music firms' incentive to produce singles. In 2004, only $19 \%$ of music firms produced a single(s) in the US, but this proportion increased to $33 \%$ in 2011.

Beginning in 2004, iTunes became available in many countries other than the US. Appendix B summarizes the history of iTunes' market entry into foreign countries. The timing of iTunes' 
introduction varies across different countries. Apple attained great success in the world music market. On the 10th of October 2012, the iTunes Store was reported to have a $64 \%$ share of the global online music market. For example, the entry of iTunes into Japan in August 2005 was successful. The popularity of singles increased significantly after the introduction of iTunes in Japan. The proportion of single-producing firms in Japan increased from 35\% in 2004 to $74 \%$ in 2011 . We use iTunes' staggered entries into 29 countries as an instrumental variable to mitigate a potential concern regarding endogeneity between single production and talent level of the artists. We further explain this issue in the following methodology section.

\section{Empirical Strategy}

\subsection{Sample}

The sample consists of all music production firms reported on the MusicBrainz database from 1995 to 2015. The sample includes only music production firms because other types of music firms lack A\&R executives or teams, who search for and recruit new artists. We choose 29 countries that have more than 200 unique music production firms in the MusicBrainz database. We exclude firm-years in which firm $i$ does not release any song at year $t$. The final sample consists of 29,317 firm-years associated with 9,667 firms; the panel is unbalanced.

\subsection{Variables}

\subsubsection{Independent variables}

When we test the first and second hypotheses, the unit of analysis is the firm-year observation. The independent variable is a dummy, Dummy_Firm_Single $i t$, that is equal to 1 when at least one release of firm $i$ is released as a single in year $t$ and is otherwise 0 . Instead of a continuous variable, we employ a dummy as the main variable because the expected quality of the most promising outside options (i.e., the expected talent level of the most talented artist among new-to-the-world artists that firms may experiment with) critically depends on whether or not firm $i$ produces at least one single (i.e., implements decomposed search) or not. To check the robustness of the results, 
we use two alternatives (continuous measures of this variable): (1) the proportion of singles to all releases of firm $i$ in year $t$ and (2) the average number of songs per release of firm $i$ in year $t$.

\subsubsection{Dependent variables}

The first dependent variable measures the number of new artists (i.e., new-to-the-world artists, Number_New_Artists ${ }_{i t}$ ) in music firm $i$ at year $t$. Second, we measure the case of missing out on talented artists after the failure of their first releases with the dummy variable, Miss_Talented_Artist ${ }_{i t}$, which is the number of artists who are part of the top $20 \%$ in lifetime popularity but experienced failure with their first release (which was not included in the top $10 \%$ of popular songs) and then moved to another firm to produce their subsequent release. The cutoffs (i.e., top $20 \%$ lifetime popularity and top $10 \%$ song popularity) are based on our interview with a former EMI producer, who notes that only $10 \%$ of releases break even, and these songs are made mostly by top $20 \%$ artists. A test of the robustness of the results to different cutoffs shows that they are qualitatively identical. We dropped 9 artists who were released after the first release and returned to the same firm for subsequent releases (i.e., artists' third or subsequent releases). We use lifetime popularity scores from the Spotify Echo Nest API and song popularity scores from the Spotify Web API. We use unique international standard recording code (ISRC) ids, song names, and artists' names for songs to match the Spotify Web API and the MusicBrainz data. As shown in Figure 2, both lifetime popularity and song popularity have skewed distributions.

-Insert Figure 2 about here-

\subsubsection{Control variables}

We control for (1) the number of songs (lag 1 year) as a firm size proxy and (2) the mean number of artists' prior releases (lag 1 year) as a firm status proxy. We also include (3) a dummy that takes the value of one if firm $i$ produced at least one top-5\% song in the previous year, (4) the Herfindahl index for music genres in firm $i,(5)$ a dummy for entrepreneurial firms (firm age $\leq 5$ ), (6) year dummies, (7) genre complexity (by following Piazzai and Wijnberg, 2019; the details are in Appendix C), (8) genre dummies, and (9) country dummies. 


\subsection{Empirical specification}

\subsubsection{Baseline OLS models and endogeneity issues}

We use OLS regressions as the baseline tests. We add a vector of control variables that might influence music firms' decisions on producing singles. Thus, our initial specification is

$$
\begin{aligned}
\text { Number_Artists } s_{i t} & =\beta_{0}+\beta_{1} \text { Dummy_Firm_Single } i t+\beta_{2} X_{i t}+C_{i}+G_{i t}+T_{t}+F_{i}+e_{i t}, \\
\text { Miss_Talented_Artists } s_{i t} & =\beta_{0}+\beta_{1} \text { Dummy_Firm_Single } e_{i t}+\beta_{2} X_{i t}+C_{i}+G_{i t}+T_{t}+F_{i}+e_{i t},
\end{aligned}
$$

where $i$ indexes firms, $t$ indexes calendar year, $X_{i t}$ is a set of observable characteristics of the firm described above as control variables, $C_{i}$ is the country fixed effect, $G_{i t}$ is the genre fixed effect, $T_{t}$ is the year fixed effect, and $F_{i}$ is the firm-fixed effect. Standard errors are clustered at the firm level.

Whereas equations (1) and (2) control for the correlation between producing singles and the control variables, concerns may still arise about selection based on omitted variables (Angrist and Pischke, 2008, Hamilton and Nickerson, 2003, Rawley and Simcoe, 2013, Semadeni, Withers, and Certo, 2014, Wooldridge, 2013). In an ideal experimental design, we would randomly assign single production status and measure the ex-post difference in the dependent variables. In practice, we observe changes in both the production of singles and the dependent variables.

\subsubsection{Two-stage least squares estimator (Instrumental variable estimators)}

We attempt to address this endogeneity and omitted variable issue by employing two-stage least squares estimators (2SLS) (Angrist and Pischke, 2008, Wooldridge, 2013). To do this, we utilize two instrumental variables: (1) the staggered introduction of iTunes and (2) the country-level proportion of albums to all releases in the previous year. In the first-stage regression, we estimate the following equation: Dummy_Firm_Single $i t=\beta_{I V} Z_{i t}+\mu_{i t}$, where $Z_{i t}$ is a set of firm characteristics, the other fixed effects, and instrumental variables, and $\mu_{i t}$ is an error term. Then, we estimate the following second-stage OLS regression model.

The second instrumental variable is the country-level proportion of albums to all releases in the previous year. As we noted earlier, in some countries, singles survived as a different format of 
music release, even in the 1990s. For example, in 1995, 47\% of UK music releases were produced as singles. In contrast, at that time, only $22 \%$ of US releases were singles. In addition, South Korea is an extreme example; no music in South Korea was produced as a single in 1995. We use this variation to complement the first instrumental variable. This instrument captures the differences in the popularity of albums (compared to singles) across countries, complementing the dummy variable for iTunes' staggered entry.

In the first stage regression, we estimate the following equation: Dummy_Firm_Single $i t=$ $\beta_{I V} Z_{i t}+\mu_{i t}$, where $Z_{i t}$ is a set of firm characteristics, the other fixed effects, and instrumental variables, and $\mu_{i t}$ is an error term. Then, we estimate the second stage OLS regression model. ${ }^{5}$

$$
\begin{aligned}
& \text { Number_Artists } s_{i t}=\beta_{0}+\beta_{1} \text { Dummy_Fîirm_Single } e_{i t}+\beta_{2} X_{i t}+C_{i}+G_{i t}+T_{t}+F_{i} \\
& +\left[\eta_{i t}+\beta_{1}\left(\text { Dummy_Firm_Single } e_{i t}-\text { Dummy_Firm_Single } e_{i t}\right]\right. \text {. } \\
& \text { Miss_Talented_Artists }{ }_{i t}=\beta_{0}+\beta_{1} \text { Dummy_Firm_Single }_{i t}+\beta_{2} X_{i t}+C_{i}+G_{i t}+T_{t}+F_{i} \\
& +\left[\eta_{i t}+\beta_{1}\left(\text { Dummy_Firm_Single } e_{i}-\text { Dummy_Fî́rm_Single } e_{i t}\right]\right. \text {. }
\end{aligned}
$$

Regarding the instrumental variables, the first instrumental variable is a dummy variable that takes a value of one if iTunes was introduced in year $t$ in country $c$ and 0 otherwise. The staggered market entry of iTunes into 29 countries offers an exogenous variation. The introduction of iTunes increases the commercial importance of the single significantly because music is sold in the form of individual songs that were previously only or primarily sold as parts of albums. As the introduction timing of iTunes and other digital services is mainly determined by the difference in intellectual property regimes between the US and local countries, rather than due to differences in countries' talent discoveries, this variable is less correlated with factors in the error term that influence music firms' decisions on experimenting with new artists.

The second instrumental variable is the country-level proportion of albums to all releases in the

\footnotetext{
${ }^{5}$ One way to estimate these two-stage equations is to manually estimate the first-stage standard errors and then plug their fitted values into the second-stage regression model. However, as Angrist and Pischke (2008) notes, the OLS standard errors from this manual approach will not be correct because these errors are the standard deviation of $\eta_{i t}+\beta_{1}\left(\right.$ Dummy_Firm_Single $e_{i t}-$ Dummy_Firm_Single $\left.i t\right)$, but the correct 2SLS standard error is the standard deviation of only $\eta_{i t}$. To avoid this mistake, we use the ivregress 2 sls and xtivreg routines in Stata because they routine correctly estimate the standard errors of the second-stage regression (Angrist and Pischke 2008).
} 
previous year. As we noted earlier, in some countries, singles survived as a different format of music release, even in the 1990s. For example, in 1995, 47\% of UK music releases were produced as singles. In contrast, at that time, only $22 \%$ of US releases were singles. Additionally, South Korea is an extreme example; no music in South Korea was produced as a single in 1995. In the countries (e.g., the UK) in which singles survived as a different music release format, music firms are more likely to produce singles than are music firms in other countries with a weak presence of single releases. For example, firms in countries such as the UK are more likely to produce singles than firms in other countries such as the US; this difference is less correlated with factors in the error term that influence music firms' decisions on experimenting with new artists. Similarly, this cross-national difference in the presence of single releases offers another variation for identification.

An ideal instrumental variable would generate firm-level variation in the incentives to produce singles. For example, A\&R managers' preference on producing singles (which could be measured as whether they discovered talented artists before by producing singles) could be a candidate for a firm-level instrumental variable. However, given the data limitation, we could not access a reliable database that summarizes the A\&R managers who participate in music production. Additionally, all other available firm-level variables (e.g., firm size, firm status, whether firms produced top 5\% popular songs in the previous year, the dummy for entrepreneurial firm) could be correlated with both production modes (i.e., singles vs. albums) and talent search strategy (i.e., new artists vs. experienced artists). For example, entrepreneurial firms are more likely to produce singles because they are less financial resources and they are more likely to experiment with new artists than are incumbent firms.

Because we do not have a firm-level instrumental variable, our identification strategy could be vulnerable to omitted variables that are correlated with both our country-level instruments and firm-level change in the discovery of new talent. However, we expect any resulting bias to be small because our specification controls for a number of time-varying observables at the firm level. 


\subsubsection{Propensity score matching}

To complement the 2SLS models, we use a matching estimator: propensity score matching. Propensity matching estimators control for selection bias by creating a matched sample of treatment and control observations that are similar to the observable characteristics (Rosenbaum and Rubin, 1983, De Figueiredo, Meyer-Doyle, and Rawley, 2013, Villalonga, 2004). To implement propensity score matching, we estimate a probit model of the firm's decision to produce singles and use fitted values from that model as estimates of the propensity score.

We calculate the propensity scores $p\left(X_{i t}\right)$ of firms in our sample and match firms with propensity scores that are within the radius caliper 0.05 . The results are robust to the use of different radius caliper values. The propensity score matching estimator for the average treatment effect on the treated is the mean difference in the number of artists at the label level and the chance of missing out on talented artists: $\delta_{\text {Number_New_Artists }}=E\left[E\left[\right.\right.$ Number_New_Artists $s_{i t} \mid$ Dummy_Firm_Single $e_{i t}=$ $\left.1, p\left(X_{i t}\right)\right]-E\left[N u m b e r \_N e w \_\right.$Artists $s_{i t} \mid$ Dummy_Firm_Single $\left.\left.e_{i t}=0, p\left(X_{i t}\right)\right]\right]$, and $\delta_{\text {Miss_Talented_Artists }}=E\left[E\left[\right.\right.$ Miss_Talented_Artists ${ }_{i t} \mid$ Dummy_Firm_Single $\left.e_{i t}=1, p\left(X_{i t}\right)\right]-$ $E\left[N u m b e r \_N e w \_A r t i s t s_{i t} \mid\right.$ Dummy_Firm_Single $\left.\left.i t=0, p\left(X_{i t}\right)\right]\right]$. For this analysis, we use the psmatch2 routine in Stata. The matched sample is consistent throughout the paper. We then trim extreme values and firm-year observations off the common support of the propensity score distribution to obtain our matched samples. The number of the matched sample in common support is 16,980. We dropped 12,337 unmatched sample. We use the matched sample to test all hypotheses and mechanisms. Kernel density distributions for before and after matching are visualized in Appendix D. Panel A shows that the distributions of propensity scores of single-producing firms and album-only-producing firms are different before matching. Panel B demonstrates that a tighter fit exists between the single-producing firms and album-only-producing firms after matching.

\subsection{Sample Statistics}

Table 3 reports the descriptive statistics on all the variables at the firm-year level. First, the descriptive statistics for the independent variables show that the proportion of firm-year observations 
that produce at least one single is $39.3 \% .{ }^{6}$ Second, the average number of new artists is 1.178 , and the variance was large (2.001). ${ }^{7}$ In addition, we report the descriptive statistics on the two instrumental variables. First, the proportion of firm-year observations for which iTunes was introduced in country $c$ is $0.587: 58.7 \%$ of firm-year observations are after the introduction of iTunes, and the other $41.3 \%$ observations are before the introduction of iTunes. Second, the average of the second instrumental variable - the country-level proportion of albums to all releases in the previous year is 0.736. Finally, correlations among the variables are provided in Appendix E.

-Insert Table 3 about here-

\section{Results}

\subsection{Does producing singles increase the number of new artists in the firm?}

We test whether producing singles increases the number of new artists in the music firm. We compare single-producing firms and album-only-producing firms. Table 4 shows the results from the tests on the impact of producing singles on the number of new artists in the firm. We estimate five different versions of the same equation: OLS with and without the control variables, propensity score weighted regression with and without the control variables, and instrumental variables analysis (2SLS). Column 1 reports the estimates from a simple OLS specification without the control variables. We find a strong correlation between producing singles and the number of new artists. The number of new artists in the firm increases by 0.62 in firms that produce some of their work as a single(s) compared to those that produce their work only as albums. The $T$ statistic of the coefficient is 13.07 , which means the $p$-value is close to 0 . Next, Column 2 shows the results from the same model after adding the control variables and other effects. The coefficient is smaller than the coefficient in Column 1 (0.4147) and is positive; the $T$ statistic of the coefficient is 13.25, meaning that the $p$-value is small.

Columns 3 and 4 present estimates from the same model after matching to control for observ-

\footnotetext{
${ }^{6}$ The proportion of artists whose first release is a single is $71.7 \%$.

${ }^{7}$ Of the artists, $15.8 \%$ had a second production chance in the single-producing firms, and $21.7 \%$ had a second production chance in the album-only-producing firms.
} 
able differences between single-producing firms and album-only-producing firms. The coefficients from these matching models are 0.4914 and 0.4761 , and their $T$ statistics are 12.52 and 12.58, respectively. In Column 5, we present estimates from the 2SLS model, which controls the potential endogeneity of producing singles using the two instrumental variables. The first-stage relationship between the introduction of iTunes and producing singles by the firm is positive ( $T$ statistic: 2.05$)$, and the first-stage relationship between country-level firms' proportion of albums to all releases in the previous year and the production of singles by the firm is strongly negative: the $T$-statistic on this instrumental variable is -11.97 . Overall, the first-stage $T$ statistics indicate powerful instruments, alleviating the concern regarding weak instruments (see, for example, Semadeni, Withers, and Certo, 2014 for summaries of this issue). Because we have more instrument variables than endogenous variables, we conduct a test of overidentifying restrictions using Sargan's $J$ statistic. The overidentification test does not reject the null hypothesis that all of our instrument variables are valid $\left(\chi^{2}(1)=1.332 ; p=0.2484\right)$, alleviating concerns about an over-identification problem. In the second stage, the estimated changes in the talent level of new artists are positive. The coefficient is 1.4955 ( $Z$ statistic: 3.12, p-value: 0.002). Our 2SLS estimate in Column 5 is noisier than

the matching estimate in Column 4, and the $Z$ statistic of the difference between the coefficient in Column $4(0.4761)$ and the coefficient in Column 5 (1.4955) is 2.13. Collectively, when firms produce singles, they experiment with more talented artists than when they produce artists' work only as albums.

-Insert Table 4 about here-

\subsection{Does producing singles increase the chance of missing out on talented new artists after their first releases?}

We turn now to the second hypothesis, which tests the impact of producing singles on missing out on talented new artists after the failure of their first releases. Here, the sample firms are those that experimented with at least one new artist in year $t$. Table 5 shows the results from the tests on the effect of single production on omission errors in giving a second chance to new artists. Column 1 reports the estimates from a simple OLS model without control variables. We find 
a positive relationship between producing singles and omission errors. Specifically, the estimate, 0.0394, in Column 1 suggests that omission errors are associated with an increase of $38.86 \%$ when firms experiment with a new artist through producing a single. ${ }^{8}$ Columns $2-4$ present consistent estimates. Regardless of matching and the presence of the control variables and other effects, the estimates have similar values: $0.0212,0.0316$, and 0.0261 . Finally, we present the estimates from the 2SLS model with the same two instrumental variables. The first-stage coefficients ( $T$ statistics) on the relationship between instrumental variables and producing singles are 0.0277 (4.68) and -0.7720 (-15.07). These coefficients and $T$ statistics indicate powerful instruments. In the second stage, the estimated changes in the omission error are positive (0.3793) with a $p$-value of 0.001 .

-Insert Table 5 about here-

\subsection{Does producing singles increase the performance target for selection and retention?}

We test a mechanism for the second hypothesis. We propose that the increased chance of missing out on talented artists may come from an increased performance target of the single production. To study the performance target, we use another dependent variable, the popularity of the most popular song in the first release (i.e., single or album) of the new artists who did not receive a second chance in the same firm. Columns 1 to 5 in Table 6 demonstrate a strong relationship between producing singles and the performance target. The coefficients $(1.5911,0.9719,0.6136$, 0.6296, and 1.6038) are positive: the $p$-values for these three estimates are $0.000,0.000,0.000$, 0.000 , and 0.029 . Because 5.2095 is the average popularity score of the most popular song of the first release produced by the new artists who did not receive a second chance in the same firm, single production is associated with a $12.50 \%(=0.6296 / 5.0337) \sim 30.79 \%(=1.6038 / 5.2095)$ increase in performance target for selection and retention.

-Insert Table 6 about here-

In Table 7, we formally test whether the performance target mediates the relationship between

\footnotetext{
${ }^{8}$ Additionally, in Appendix F, we run the same OLS regression with the subsample of firms that discovered a top $20 \%$ popular artist. The estimate is 0.0782 , and the effect size is an increase of $15.29 \%(=0.0782 / 0.5116)$.
} 
single production (i.e., independent variable) and omission errors in giving a second chance to a top $20 \%$ popular artist (i.e., dependent variable). Sobel (1982) formulated a significance test for the indirect impact of the independent variable on the dependent variable through the mediator. The subsequent literature has christened it the "Sobel test" (e.g., Baron and Kenny, 1986). Specifically, the coefficient of the path from the independent variable to the mediator is denoted as $\beta_{a}$, and its standard error is $S E_{a} ; \beta_{a}$ and $S E_{a}$ were estimated in Table 6. The statistics in Columns 1-4 show that the mediation path explains $19.80 \%, 17.92 \%, 24.37 \%$, and $15.71 \%$ of the relationship between single production and the omission errors in giving a second chance to a top $20 \%$ popular artist. The coefficient of the path from the mediator to the dependent variable is denoted as $\beta_{b}$, and its standard error is $S E_{b} ; \beta_{b}$ and $S E_{b}$ are estimated in Table 7 Panel A. In the first four

regression models in Table 5 and $6,{ }^{9}$ the Sobel test statistics $\left(\beta_{a} \times \beta_{b}\right) / \sqrt{\left(\beta_{b}^{2} \times S E_{a}^{2}\right)+\beta_{a}^{2} \times S E_{b}^{2}}$ $(7.8163,2.3735,2.5497,2.2276)$ and their $p$-values $(0.000,0.018,0.011,0.026)$ are estimated and presented in Table 7 Panel B. Overall, the statistics show that the performance target mediates the relationship between single production and the omission errors in giving a second chance to a top $20 \%$ popular artist at least $p$-value $=0.026$.

-Insert Table 7 about here-

\subsection{Boundary conditions and robustness checks}

Boundary conditions for Hypothesis 2: We explore boundary conditions under which single production increases the chance of making omission errors when giving a second chance to a talented artist. We test two boundary conditions: (1) established firms versus entrepreneurial firms and (2) pop music genres (i.e., Pop, Hip-hop, Rock, and Funksoul) versus other niche genres.

First, established firms have more alternative options because would-be artists are more interested in getting signed with established firms primarily because established firms have more financial and relational resources than entrepreneurial firms (Passman 2003). Thus, we can predict that the talent level of the most promising alternative option (the popularity level of the most popular artists that the firm might discover) of established firms could increase more if the firm

\footnotetext{
${ }^{9}$ The Sobel test for the instrumental variable estimators (2SLS) has yet to be developed.
} 
produces single(s) than if entrepreneurial firms do so. Established firms might have a higher performance target and experience more omission errors than entrepreneurial firms. Table 8 Panel A supports these predictions. The coefficients $(0.0363,1.4338)$ for the established firms are positive and larger than the coefficients $(0.0119,0.6780)$ for the entrepreneurial firms.

Second, there are more would-be artists for pop music genres (Pop, Hip-hop, Rock, and Funksoul) (Resnikoff, 2016). Firms whose main genre is one of the pop genres will encounter more outside options, leading to a higher performance target. Therefore, they will experience more omission errors compared with firms whose main genre is not one of the pop genres (e.g., Alternative, Jazz, Reggae, Folk, etc.). Table 8 Panel B supports these predictions. The coefficients $(0.0362,1.3721)$ for the established firms are positive and larger than the coefficients $(0.0229,1.0108)$ for the entrepreneurial firms.

-Insert Table 8 about here-

Difference in the quality of experimented alternatives: When firms produce singles, firms may experiment with different types of talent whose potential may be higher than when they produce albums. Because of the high uncertainty in predicting the talent of an artist before production and commercialization in the music industry, the term "nobody knows principle" has been coined by industry experts (Caves, 2000). Therefore, it is unlikely that the single production itself may bring more talented artists than album production. One way to rule out this concern is by comparing the talent levels of new artists between single-producing firms and album-only-producing firms. We analyze two different samples: firm-level sample and artist-level sample.

We do not find a strong relationship between producing singles and the average talent level of new artists. Table 9 Columns 1 to 3 report estimates from the firm-level analysis. Although the coefficients $(0.0654,0.0905$, and 2.5758) are positive, the $p$-values for these three estimates are 0.792 , 0.715, and 0.142. Columns 4 to 6 report estimates from the artist-level analysis. The results are similar. The first two coefficients $(-0.0058$ and -0.0133$)$ are negative, but the $p$-values for these two estimates are 0.925 and 0.831. Although the coefficient in Column 6 (2SLS) is positive (1.4064), the $p$-value of the coefficient is 0.670 . In sum, we find no evidence for a difference in the average quality of the new artists for whom firms experimented with a single production. 
-Insert Table 9 about here-

Noisier quality signal from single production: The increase in the omission errors may come from a nosier quality signal of the single production. In reality, even though music firms allow an artist to produce an album, the firms focus on one title song in the commercialization process. Thus, albums also produce a similarly noisy signal on the talent of new artists. One way to rule out this concern is by considering commission errors in giving second chances to untalented artists. If single production generates a noisier signal than album production, we would see that single-producing firms make more commission errors in giving a second chance to new artists (as well as omission errors in giving second chances). In the presence of a noisier signal (from single production), new artists will be more likely to face lucky draws as well as unlucky draws. However, if our mechanism works (i.e., the single production is associated with a higher performance target), we will see fewer commission errors because of the increased performance target for selection and retention.

Table 10 shows that the patterns regarding commission errors are more consistent with our suggested theoretical mechanism than the alternative story (i.e., the noisier-signal story). The results suggest that single production decreases the chance of making commission errors because single production increases the performance target for selection and retention. Columns 1 to 5 report estimates from the models for which the dependent variable is the number of bottom $80 \%$ artists who were given a second chance in firm i. The coefficients $(-0.0977,-0.1161,-0.1030,-0.1025$, and -0.4216$)$ are negative; the p-values for these three estimates are 0.000 .

\section{-Insert Table 10 about here-}

Escalation of commitment: Another alternative explanation for $\mathrm{H} 2$ could be the escalation of commitment in sequential investment, a type of limitation in information processing (e.g., Staw, 1976, Brockner 1992, Wong and Kwong, 2018). The escalation of commitment is a behavioral bias in which an individual or a firm facing negative outcomes from an investment nevertheless continues the behavior instead of terminating the investment (e.g., McNamara, Moon, and Bromiley, 2002, Guler, 2007, Egger, 2012). Thus, when firms produce albums (which requires more resource commitment), they are more likely to continue their commitment (i.e., fewer omission errors in giving 
a second chance) than when they produce singles.

One way to rule out this concern is by examining commission errors across different commitment levels. We examine the different commitment levels by comparing solo and group artists. Experimenting with a group ( $>1$ person) usually requires more financial commitment than experimenting with a solo artist (Passman, 2003). For example, the amount of the cash advance increases as the number of people in the group increases. If the escalation of commitment explains the observed pattern when a firm experiments with a group, the firm will be more likely to make a commission error when giving a second chance (e.g., giving a second chance to the bottom $80 \%$ popular ones) than when the firm experiments with a solo artist.

For solo artists, the chance of making commission errors is $47.80 \%$; for group artists, the chance of making commission errors is $46.66 \%$. Making commission errors for solo artists is as likely as making commission errors for groups. The patterns regarding commission errors in Table 11 are more consistent with our suggested theoretical mechanism than the escalation of commitment story. Panel A and B show the results of the subsamples of solo artists and groups, respectively. Columns 1 to 5 report estimates of the impact of single production on making commission errors, whose variable takes the value of one if the same firm gives a second chance to the bottom $80 \%$ popular artists. The coefficients $(-0.2650,-0.0209,-0.4171,-0.0244$, and -0.0569) in Panel A are not smaller than the coefficients $(-0.3314,-0.0284,-0.6959,-0.1019$, and -0.0585$)$ in Panel B, suggesting that firms do not make more commission errors when they produce singles for groups than they do for solo artists.

-Insert Table 11 about here-

Other robustness checks: Our findings are robust to the use of alternative measures for the independent variable: the average number of songs per release (Appendix G), and the proportion of singles to all releases in firm $i$ (Appendix $\mathrm{H}$ Panel A). The results are qualitatively identical to the results for our baseline models, alleviating concerns about the measure of our independent variable. Also, our findings are robust to the use of the different cutoff levels for measuring the chance of missing out on talented artists. Appendix H Panel B shows that the results are robust to the different cutoff levels for measuring talented artists: top 20\%, top 15\%, top 10\%, and top $5 \%$. 


\section{Discussion and Conclusions}

We explore the two opposite effects of a decomposed search by dividing the discovery process into (1) the variation generation stage and (2) the selection and retention stages. First, we predict that the decomposed search generates more variations, some of which turn out to be promising options. However, the decomposed search might lead to worse selection and retention; a larger number of promising options could be missed after an initial evaluation for two reasons. First, in the presence of noise, as firms experiment with more alternatives, more alternatives will face an unlucky draw in their initial evaluations. Promising alternatives are not exceptions to this tendency; some will also face an unlucky draw and be evaluated as unpromising despite their underlying quality. Second, we argue that a decomposed search might increase the performance target because implementing a decomposed search increases the number of outside options that firms can experiment with, resulting in a higher expected quality of the best option among these outside options.

Our findings demonstrate that music firms that produce some of their products as singles tend to experiment with more new artists. However, they are more likely to miss out on talented artists who experienced failures in their first releases. In sum, a decomposed search generates a trade-off between variation (i.e., experimenting with more options) and selection and retention (i.e., missing out on promising options after decomposed experimentations). Specifically, approximately $80 \%$ of the increase in neglecting top-tier artists came from the increases in the number of new artists experimented with (because of a single production), and the other $20 \%$ of the increase came from a higher performance target.

One of the general approaches for search effectiveness is to decompose the overall problem into subproblems (Simon, 1962). Prior theoretical work has explored the performance implications of partitioning a system into subsystems by focusing on whether a decomposed or integrated search is superior (e.g., Levinthal and Warglien, 1999), how to solve coordination problems between modules under high complexity (e.g., Rivkin and Siggelkow, 2003), and how granular each module should be to solve a complex problem (e.g., Ethiraj and Levinthal 2004). This stream of work has utilized

the simulation methodology and has been based on two common assumptions: (1) a decomposed search facilitates experimentations, and (2) managers would not change their performance target 
no matter whether their search mode is a decomposed or an integrated search. In this study, we explore whether these two assumptions represent search behavior in the real world. By exploring these assumptions, we attempt to enhance our understanding of this topic.

First, we provide evidence that is consistent with the first assumption that a decomposed search facilitates the creation of more variations through parallel experimentations. The decomposability perspective provides a nuanced theory on parallel experimentations. Starting with the work of Nelson (1961), strategy scholars have examined the role of parallel experimentation in the discovery of new solutions (e.g., Ethiraj and Levinthal, 2004, Eggers, 2012, Posen et al., 2012). Our theory highlights that decomposability has been missing from the characterization of heterogeneous parallel experimentation. Indeed, our findings demonstrate that decomposability would be one of the main factors facilitating parallel experimentations. Additionally, this study speaks to the burgeoning empirical literature on decomposability and complexity (e.g., Zhou, 2011, Piazzai and Wijnberg, 2019, Ethiraj and Zhou, 2019). As Baumann et al. (2019) note, to date, this theoretical work has been only incidentally complemented by empirical research, and the theoretical and empirical studies remain rather disconnected. We attempt to tighten the link between theoretical and empirical work by analyzing an unusual setting to measure decomposability and its role in discovering new promising alternatives.

More importantly, regarding the second assumption, this study speaks to the literature on the performance target and aspiration level (e.g., Cyert and March, 1963, Bromiley 1991, Lant et al., 1992, Greve, 2003, Keum and Eggers, 2018). Changes in search behavior in response to the performance below the performance target have been an active research topic in organizational learning (Greve and Gaba, 2017). Although there have been studies on the ramifications of financial performance aspirations (e.g., ROE, ROS, and ROA) on subsequent firm behaviors (e.g., Audia and Greve 2006, Chen and Miller, 2007), as Shinkle (2012) notes, "the literature lacks robust empirical evidence on the antecedents of aspirations[performance targets]. Most studies rely on the formal theoretical model of behavioral theory to infer aspiration levels[performance targets]." Our study provides empirical evidence and a theoretical argument that decomposability plays an important role in shaping the performance target. Our finding highlights that the performance target plays 
an essential role in search, especially under imperfect evaluation. With these findings, this study bridges two core tenets of the behavioral theory of the firm: the tenet of the architecture on complexity (e.g., Simon 1962, Ethiraj and Levinthal, 2004, Fang and Kim, 2018) and the tenet of the performance target and aspiration level (e.g., Cyert and March, 1963, Greve, 2003).

Finally, this study speaks to the literature on the role of noise in performance evaluation (e.g., Cyert and March 1963, Adner and Helfat, 2003, Denrell, Fang, Liu, 2014). Prior studies on imperfect evaluation have examined the bias and performance implications of the heterogeneity in forecasting ability (e.g., Makadok and Walker, 2000, Denrell and Fang, 2010) and organization structure (Sah and Stiglitz, 1986, Knudsen and Levinthal, 2007, Csaszar, 2012). We consider a decomposed search as a heuristic to complement forecasting abilities or organization structure. We highlight a hidden drawback of decomposed search in search.

This study has several limitations. For instance, we have little to say about the origins of heterogeneous qualities of alternatives. We treat the quality of an alternative as an exogenous endowment akin to a gift to an artist. Extending on the theoretical framework to endogenize the quality of alternatives, including matching among firms and artists, skill, style, or knowledge gained as the outcome of a learning process in the firm, would be interesting avenues of exploration. However, they are beyond the scope of this work. Additionally, given the data limitation, we cannot observe pre-commercialization experimentations. Thus, future research might build comparable data on pre-commercialization experimentations and improve our understanding of the differences between pre- and post-commercialization experimentations. 


\section{References}

Adner, R, \& Helfat, C. E. (2003). Corporate effects and dynamic managerial capabilities. Strategic Management Journal, 24(10), pp.1011-1025.

Angrist, J.D. \& Pischke, J. S., (2008). Mostly Harmless Econometrics. Princeton university press. Audia, P. G. \& Greve, H. R., (2006). Less likely to fail: Low performance, firm size, and factory expansion in the shipbuilding industry. Management Science, 52(1), pp.83-94.

Baldwin, C. Y, \& Clark K. B. (2000). Design Rules: The Power of Modularity. MIT press, Cambridge, MA.

Baron, R.M. \& Kenny, D.A., 1986. The moderator-mediator variable distinction in social psychological research: Conceptual, strategic, and statistical considerations. Journal of Personality and Social Psychology, 51(6), p.1173.

Baumann, O., Schmidt, J., \& Stieglitz, N. (2019). Effective search in rugged performance landscapes: A review and outlook. Journal of Management, 45(1), pp.285-318.

Benner, M. J., \& Waldfogel, J. (2016). The song remains the same? Technological change and positioning in the recorded music industry. Strategy Science, 1(3), pp.129-147.

Brockner, J. (1992). The escalation of commitment to a failing course of action: Toward theoretical progress. Academy of Management Review, 17(1), pp.39-61.

Bromiley, P., (1991). Testing a causal model of corporate risk taking and performance. Academy of Management Journal, 34(1), pp.37-59.

Britt, B. (1989). The 45-rpm single will soon be history. Los Angeles Daily News, p.4.

Caves, R. E. (2000). Creative Industries: Contracts between Art and Commerce. Harvard University Press, Cambridge, MA.

Caves, R. E., (2003). Contracts between art and commerce. Journal of Economic Perspectives, $17(2)$, pp.73-83.

Chen, W. R. \& Miller, K. D., (2007). Situational and institutional determinants of firms' R\&D search intensity. Strategic Management Journal, 28(4), pp.369-381.

Csaszar, F. A. (2012). Organizational structure as a determinant of performance: Evidence from mutual funds. Strategic Management Journal, 33(6), pp.611-632.

Coyle, D., (2004). Sex, Drugs, $\&$ Economics. West Stockbridge, MA: Texere.

Cyert, R. M., \& March, J. G. (1963). A Behavioral Theory of the Firm. Prentice-Hall, Englewood Cliffs, NJ.

De Figueiredo, R.J., Meyer-Doyle, P. \& Rawley, E., (2013). Inherited agglomeration effects in hedge fund spawns. Strategic Management Journal, 34(7), pp.843-862.

Denrell, J., \& March, J. G. (2001). Adaptation as information restriction: The hot stove effect. Organization Science, 12(5), pp.523-538.

Denrell, J., \& Fang, C. (2010). Predicting the next big thing: Success as a signal of poor judgment. Management Science, 56(10), pp.1653-1667.

Denrell, J., Fang, C., \& Liu, C. (2014). Perspective - Chance explanations in the management sciences. Organization Science, 26(3), pp.923-940.

Eggers, J. P. (2012). Falling flat failed technologies and investment under uncertainty. Administrative Science Quarterly, 57(1), pp.47-80.

Eggers, J. P., \& Green, E. (2012). Choosing not to choose: A behavioral perspective on parallel search. DRUID 2012 Conference Proceeding, June (Vol. 19).

Ethiraj, S. K., \& Levinthal, D. (2004). Modularity and innovation in complex systems. Management Science, 50(2), pp.159-173.

Ethiraj, S. K., Levinthal, D., \& Roy, R. R. (2008). The dual role of modularity: Innovation and imitation. Management Science, 54(5), pp.939-955.

Ethiraj, S. K., \& Zhou, Y. M. (2019). Fight or flight? Market positions, submarket interdependencies, and strategic responses to entry threats. Strategic Management Journal, 40(10), pp.1545-1569 Ewens, M., Nanda, R., \& Rhodes-Kropf, M. (2018). Cost of experimentation and the evolution of venture capital. Journal of Financial Economics, 128(3), pp.422-442.

Fang, C., \& Kim, J. J. (2018). The power and limits of modularity: A replication and reconciliation. Strategic Management Journal, 39(9), pp.2547-2565. 
Fang, C., Kim, J. J., \& Milliken, F. J. (2014). When bad news is sugarcoated: Information distortion, organizational search and the behavioral theory of the firm. Strategic Management Journal, 35(8), pp.1186-1201.

Gaba, V. \& Joseph, J., (2013). Corporate structure and performance feedback: Aspirations and adaptation in M-form firms. Organization Science, 24(4), pp.1102-1119.

Ganco, M. (2013). Cutting the Gordian knot: The effect of knowledge complexity on employee mobility and entrepreneurship. Strategic Management Journal, 34(6), pp.666-686.

Guler, I. (2007). Throwing good money after bad? Political and institutional influences on sequential decision making in the venture capital industry. Administrative Science Quarterly, 52(2), pp.248-285.

Guralnick, P. (2012). Last Train to Memphis: the Rise of Elvis Presley. Little, Brown.

Greve, H. R. (2003). A behavioral theory of R\&D expenditures and innovations: Evidence from shipbuilding. Academy of Management Journal, 46(6), pp.685-702.

Greve, H.R. \& Gaba, V. (2017). Performance feedback in organizations and groups: Common themes. The Oxford Handbook of Group and Organizational Learning, pp.1-45.

Hamilton, B. H. \&, Nickerson J. A. (2003). Correcting for endogeneity in strategic management research. Strategic Organization, 1(1), pp.51-78.

International Federation of Phonographic Industry. (2015). IFPI releases definitive statistics on global market for recorded music. http://www.ifpi.org/sitecontent/publications/rin_order.html. [(August 2) London, UK].

Kauffman, S. (1996). At Home in the Universe: The Search for the Laws of Self-organization and Complexity. Oxford University Press. UK.

Keum, D. D., \& Eggers, J. P. (2018). Setting the bar: The evaluative and allocative roles of organizational aspirations. Organization Science, 29(6), pp.1170-1186.

Keum, D. D., \& See, K. E. (2017). The influence of hierarchy on idea generation and selection in the innovation process. Organization Science, 28(4), pp.653-669.

Knudsen, T., \& Levinthal, D. A. (2007). Two faces of search: Alternative generation and alternative evaluation. Organization Science, 18(1), pp.39-54.

Kogut, B., \& Bowman, E. H. (1995). Modularity and permeability as principles of design (pp. 243260). Redesigning the Firm, New York: Oxford Univ. Press.

Kogut, B., \& Kulatilaka, N. (1994). Operating flexibility, global manufacturing, and the option value of a multinational network. Management Science, 40(1), pp.123-139.

Kulkarni, D., \& Simon, H. A. (1990). Experimentation in machine discovery. Computational Models of Scientific Discovery and Theory Formation (edited by Jeff Shrager and Pat Langley).

Lant, T., \& Shapira, Z. (2008). Managerial reasoning about aspirations and expectations. Journal of Economic Behavior \& Organization, 66(1), pp.60-73.

Leiponen, A., \& Helfat, C. E. (2010). Innovation objectives, knowledge sources, and the benefits of breadth. Strategic Management Journal, 31(2), pp.224-236.

Lee, E., \& Puranam, P. (2016). The implementation imperative: Why one should implement even imperfect strategies perfectly. Strategic Management Journal, 37(8), pp.1529-1546.

Levinthal, D. A. (1997). Adaptation on rugged landscapes. Management Science, 43(7), pp.934-950. Levinthal, D. A., \& Warglien, M. (1999). Landscape design: Designing for local action in complex worlds. Organization Science, 10(3), pp.342-357.

Loch, C. H., Terwiesch, C., \& Thomke, S. (2001). Parallel and sequential testing of design alternatives. Management Science, 47(5), pp.663-678.

McNamara, G., Moon, H., \& Bromiley, P. (2002). Banking on commitment: Intended and unintended consequences of an organization's attempt to attenuate escalation of commitment. Academy of Management Journal, 45(2), pp.443-452.

Makadok R., \& Walker G. (2000). Identifying a distinctive competence: forecasting ability in the money fund industry. Strategic Management Journal, 21(8), pp.853-864.

March, J. G. (1991). Exploration and exploitation in organizational learning. Organization Science, 2(1), pp.71-87. 
Marengo, L., Dosi, G., Legrenzi, P., \& Pasquali, C. (2000). The structure of problem-solving knowledge and the structure of organizations. Industrial and Corporate Change, 9(4), pp.757-788.

Nelson, R. R. (1961). Uncertainty, learning, and the economics of parallel research and development efforts. The Review of Economics and Statistics, pp.351-364.

Nelson, R. R. \& Winter, S.G., (1978). Forces generating and limiting concentration under Schumpeterian competition. The Bell Journal of Economics, pp.524-548.

Passman, D. S., (2014). All You Need to Know about the Music Business. Simon and Schuster. Piazzai, M., \& Wijnberg, N. M. (2019). Product proliferation, complexity, and deterrence to imitation in differentiated-product oligopolies. Strategic Management Journal, 40(6), pp.945-958.

Posen, H. E, \& Levinthal, D. A. (2012). Chasing a moving target: Exploitation and exploration in dynamic environments. Management Science, 58(3), pp.587-601.

Posen, H. E, Martignoni, D, \& Levinthal, D. A. (2013). E Pluribus Unum: Organizational Size and the Efficacy of Learning. Available at SSRN 2210513.

Rawley, E., \& Simcoe, T. S. (2013). Information technology, productivity, and asset ownership: Evidence from taxicab fleets. Organization Science, 24(3), pp.831-845.

Ries, E. (2011). The Lean Startup: How Today's Entrepreneurs Use Continuous Innovation to Create Radically Successful Businesses. Currency.

Rivkin, J. W., \& Siggelkow, N. (2003). Balancing search and stability: Interdependencies among elements of organizational design. Management Science, 49(3), pp.290-311.

Rosenbaum, P. R. and Rubin, D. B., (1983). The central role of the propensity score in observational studies for causal effects. Biometrika, 70(1), pp.41-55.

Sah, R. K., \& Stiglitz, J. E. (1986). The architecture of economic systems: Hierarchies and polyarchies. The American Economic Review, pp.716-727.

Semadeni, M., Withers, M. C., \& Trevis Certo, S. (2014). The perils of endogeneity and instrumental variables in strategy research: Understanding through simulations. Strategic Management Journal, 35(7), pp.1070-1079.

Shinkle, G.A., (2012). Organizational aspirations, reference points, and goals: Building on the past and aiming for the future. Journal of Management, 38(1), pp.415-455.

Simon, H. A. (1955). A behavioral model of rational choice. Quarterly Journal of Economics, 69, pp.99-118.

Simon, H. A. (1962). The architecture of complexity. Proceedings of American Philosophical Society, 106, pp.467-482.

Staw, B. M. (1976). Knee-deep in the big muddy: A study of escalating commitment to a chosen course of action. Organizational Behavior and Human Performance, 16(1), pp.27-44.

Sobel, M. E., 1982. Asymptotic confidence intervals for indirect effects in structural equation models. Sociological Methodology, 13, pp.290-312.

Thomke, S. H. (2003). Experimentation matters: unlocking the potential of new technologies for innovation. Harvard Business Press, Cambridge, MA.

Thomke, S, Von Hippel, E., \& Franke, R. (1998). Modes of experimentation: an innovation process and competitive variable. Research Policy, 27(3), pp.315-332.

Tervio, M. (2009). Superstars and mediocrities: Market failure in the discovery of talent. The Review of Economic Studies, 76(2), pp.829-850.

Villalonga, B., (2004). Does diversification cause the" diversification discount"?. Financial Management, 33(2), pp.5-27.

Wong, K. F. E., \& Kwong, J. Y. (2018). Resolving the judgment and decision-making paradox between adaptive learning and escalation of commitment. Management Science, 64(4), pp.1911-1925. Wooldridge, J. M., (2013). Introductory Econometrics: A Modern Approach. Cengage learning. Zhou, Y. M. (2011). Synergy, coordination costs, and diversification choices. Strategic Management Journal, 32(6), pp.624-639.

Zollo, M., \& Winter, S. G. (2002). Deliberate learning and the evolution of dynamic capabilities. Organization Science, 13(3), pp.339-351. 
Figure 1: Decomposed search vs. integrated search in performance target and omission errors after first evaluation

Panel A. Decomposed search and omission errors after first evaluation

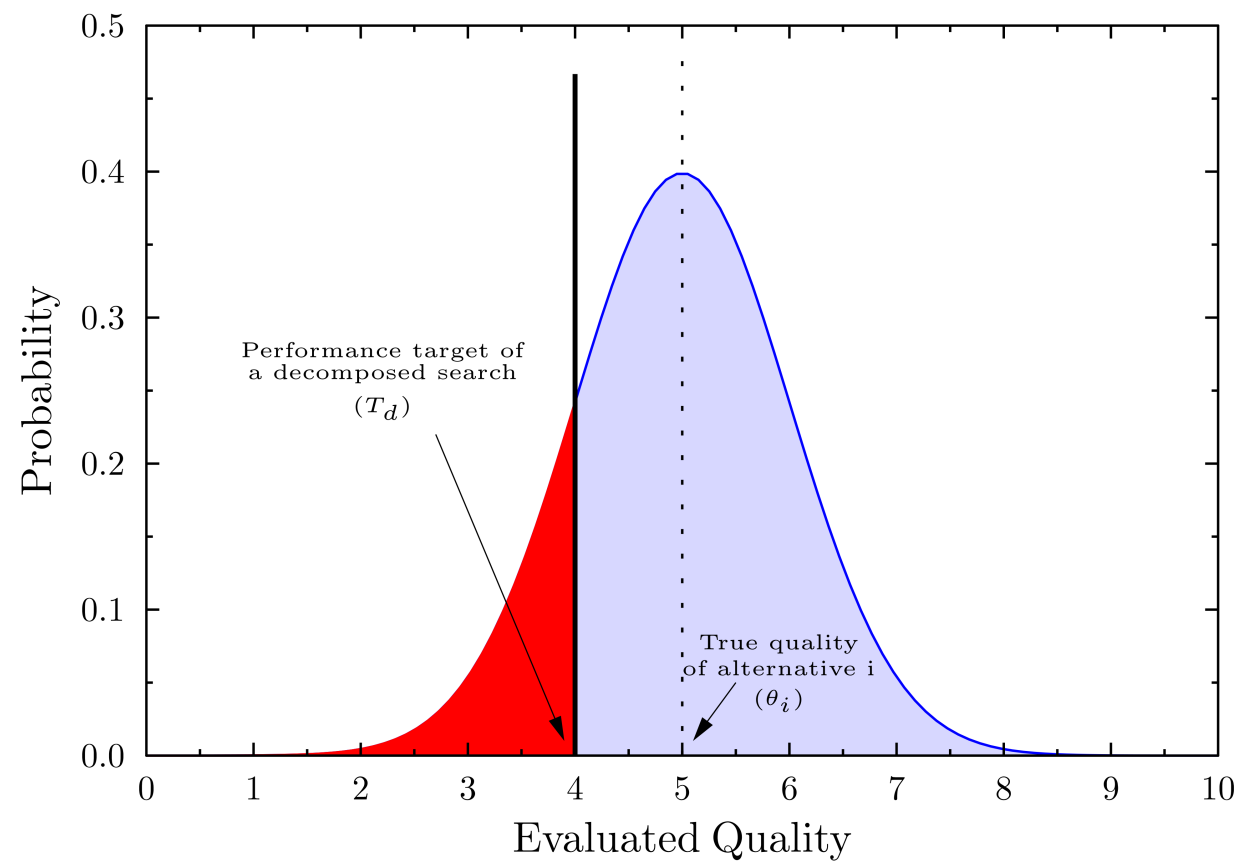

Panel B. Integrated search and omission errors after first evaluation

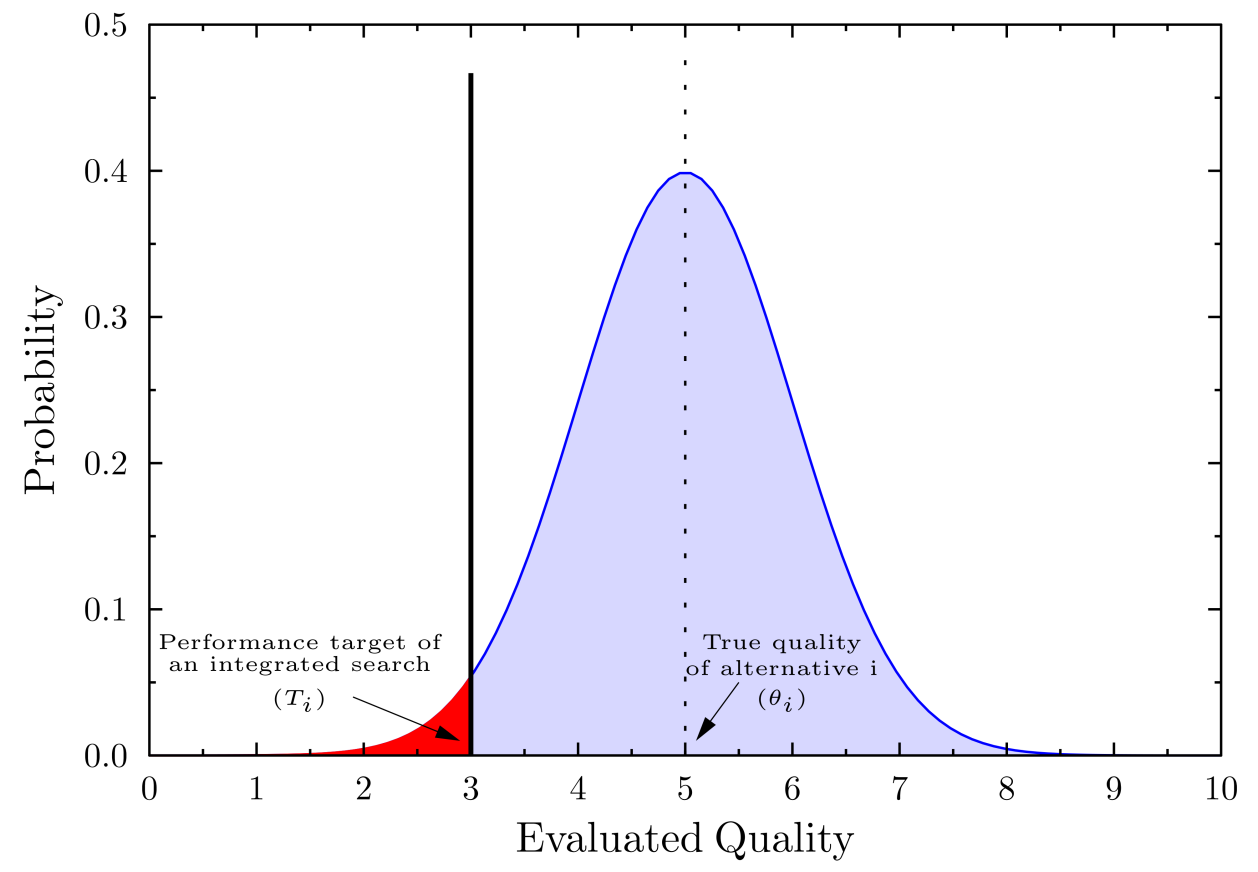

Note: The true quality of alternative $i$ is 5 , and the evaluated performance of an alternative is a random draw from a normal distribution $(N(5,1))$. The dark-colored (red-colored) area means the cases of the omission errors in giving second evaluation chances to an alternative. 
Figure 2: Popularity distributions

Panel A. Artist lifetime popularity distribution

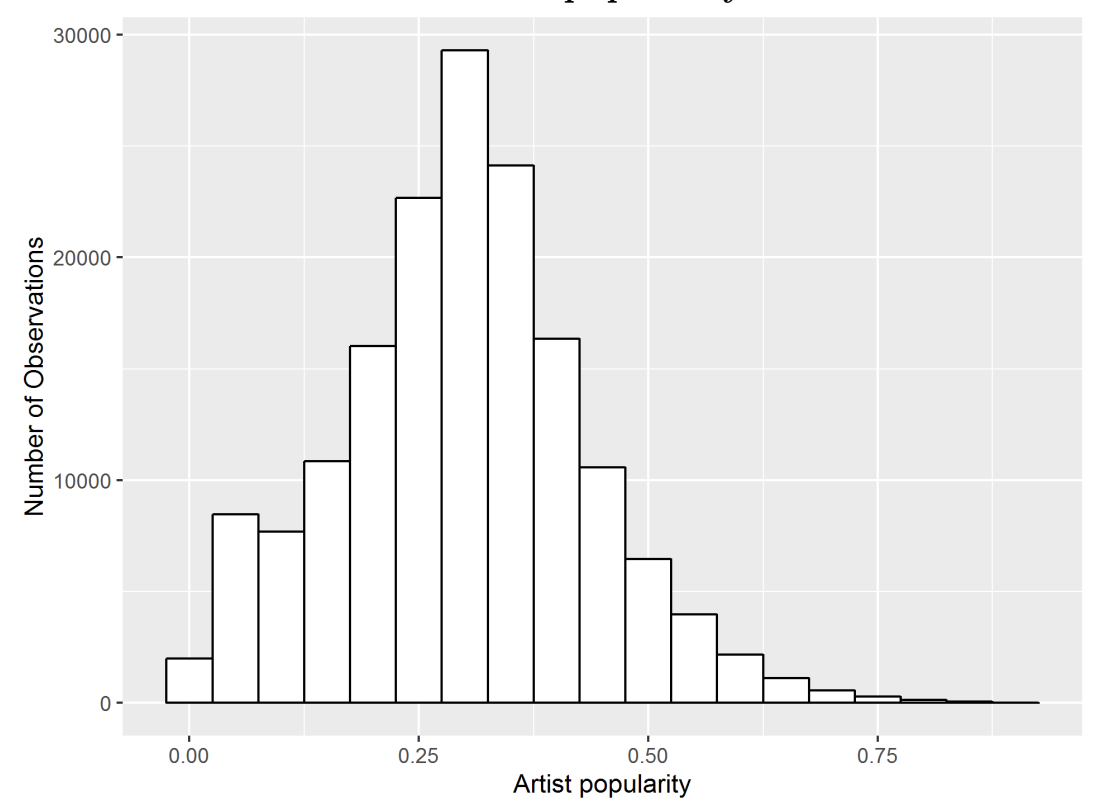

Panel B. Song popularity distribution

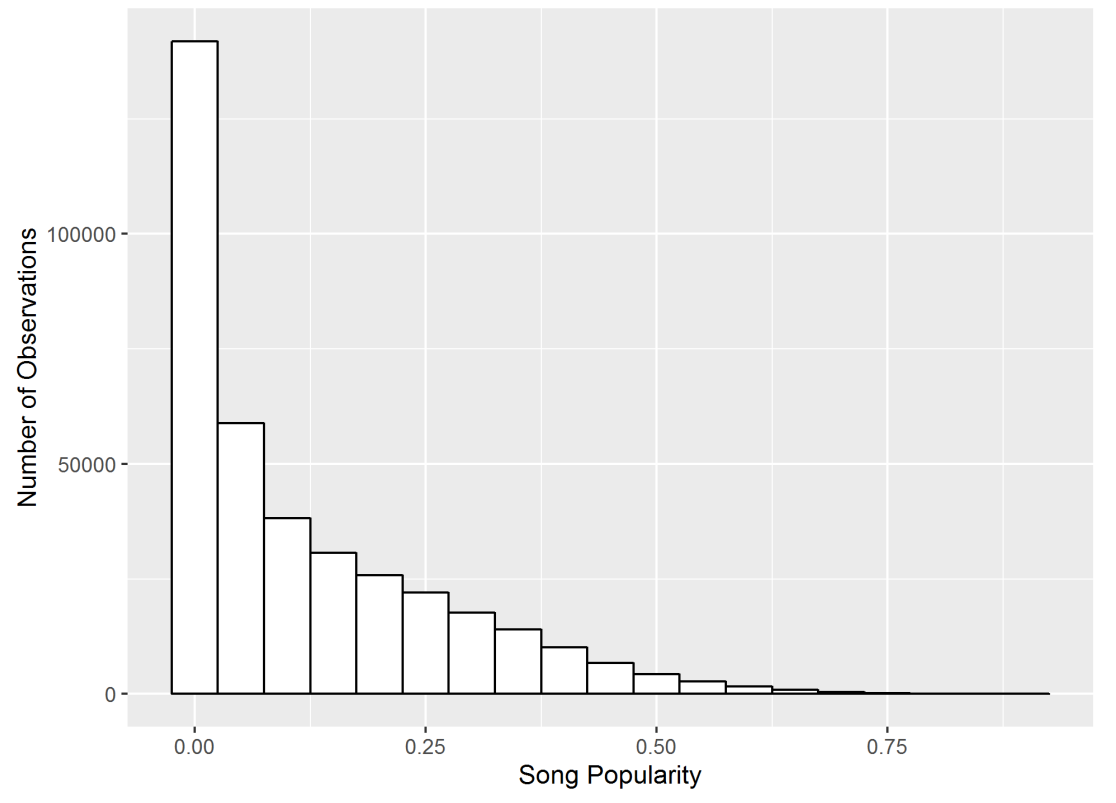

Note: We excluded observations with popularity 0 from both distributions. Figure 2 shows that popularity distributions are highly skewed. Also, it demonstrates that the song popularity distribution in Panel B is more skewed than the artist lifetime popularity in Panel A. 
Table 1: Cost of producing a release in the music industry

\begin{tabular}{l|c}
\hline \hline Item & Cost \\
\hline Cash advance & US $\$ 50,000-350,000$ \\
Recording & US $\$ 150,000-500,000$ \\
Video production & US $\$ 50,000-300,000$ \\
Tour support & US $\$ 50,000-150,000$ \\
Marketing and promotion & US $\$ 200,000-700,000$ \\
\hline Total & US $\$ 500,000-\$ 2,000,000$ \\
\hline
\end{tabular}

Source: International Federation of the Phonographic Industry report, 2014

Table 2: Link between theoretical constructs and empirical context

\begin{tabular}{|c|c|c|}
\hline Theoretical construct & $\begin{array}{c}\text { Implementing a } \\
\text { decomposed search }\end{array}$ & $\begin{array}{l}\text { Implementing only an } \\
\text { integrated search }\end{array}$ \\
\hline Empirical definition & $\begin{array}{l}\text { Music firms producing singles } \\
\text { and album(s) }\end{array}$ & Music firms only producing album(s) \\
\hline Sample proportion & $39.3 \%$ of the sample firm-years & $60.7 \%$ of the sample firm-years \\
\hline Variation generation & $\begin{array}{l}\text { Producing and commercializing } \\
\text { the first single or first album } \\
\text { of each artist }\end{array}$ & $\begin{array}{c}\text { Producing and commercializing } \\
\text { the first album } \\
\text { of each artist }\end{array}$ \\
\hline Selection and retention & $\begin{array}{c}\text { Giving a second chance } \\
\text { (production and } \\
\text { commercialization) to an artist } \\
\text { after evaluating the commercial } \\
\text { outcomes of the first release }\end{array}$ & $\begin{array}{l}\text { Giving a second chance } \\
\text { (production and } \\
\text { commercialization) to an artist } \\
\text { after evaluating the commercial } \\
\text { outcomes of the first release }\end{array}$ \\
\hline $\begin{array}{l}\text { H1-Dependent variable: } \\
\text { Number of new artist }\end{array}$ & $\begin{array}{l}\text { Prediction: Experimenting with } \\
\text { more new artists due to the low } \\
\text { cost of experimentation }\end{array}$ & $\begin{array}{l}\text { Prediction: Experimenting with } \\
\text { fewer new artists due to the } \\
\text { high cost of experimentation }\end{array}$ \\
\hline $\begin{array}{l}\text { H2-Dependent variable: } \\
\text { Number of talented } \\
\text { artists who were missed } \\
\text { after producing and } \\
\text { commercializing their } \\
\text { first release }\end{array}$ & $\begin{array}{l}\text { Prediction: Missing out on a } \\
\text { larger number of the top } 20 \% \\
\text { talented artist(s) if their } \\
\text { song popularity is below the top } \\
10 \% \text { popularity score }\end{array}$ & $\begin{array}{l}\text { Prediction: Missing out on a } \\
\text { smaller number of the top } 20 \% \\
\text { talented artist(s) if their } \\
\text { song popularity is below the top } \\
10 \% \text { popularity score }\end{array}$ \\
\hline
\end{tabular}


Table 3: Summary statistics

\begin{tabular}{|c|c|c|c|c|c|}
\hline Variable name & $\begin{array}{c}\text { Level of } \\
\text { Variation }\end{array}$ & Mean & $\begin{array}{l}\text { Std. } \\
\text { Dev. }\end{array}$ & Min. & Max. \\
\hline $\begin{array}{l}\text { Independent variables: } \\
\text { (Dummy) one if firm produces at least one single }\end{array}$ & Firm & 0.393 & 0.488 & 0 & 1 \\
\hline $\begin{array}{l}\text { Dependent variables: } \\
\text { Number of new artists } \\
\text { Number of top } 20 \% \text { talented artists whom firm missed out on } \\
\text { after their first release }\end{array}$ & $\begin{array}{l}\text { Firm } \\
\text { Firm }\end{array}$ & $\begin{array}{l}1.178 \\
0.036\end{array}$ & $\begin{array}{l}2.001 \\
0.314\end{array}$ & $\begin{array}{l}0 \\
0\end{array}$ & $\begin{array}{l}52 \\
11\end{array}$ \\
\hline $\begin{array}{l}\text { Other variables: } \\
\text { (Dummy) one if iTunes was introduced in country } c \\
\text { County-level proportion of albums to all releases (year } t-1) \\
\text { Complexity of firm main genre } \\
\log \text { (Number of songs) } \\
\log \text { (Mean number of artists' prior releases) } \\
\text { (Dummy) one if firm produced at least one top } 5 \% \text { song (year } t-1 \text { ) } \\
\text { Herfindahl index for genre in firm } \\
\text { (Dummy) one if firm is an entrepreneurial firm }\end{array}$ & $\begin{array}{c}\text { Country } \\
\text { Country } \\
\text { Genre } \\
\text { Firm } \\
\text { Firm } \\
\text { Firm } \\
\text { Firm } \\
\text { Firm }\end{array}$ & $\begin{array}{c}0.587 \\
0.736 \\
33.740 \\
2.534 \\
1.059 \\
0.039 \\
0.893 \\
0.493\end{array}$ & $\begin{array}{l}0.492 \\
0.141 \\
1.143 \\
1.498 \\
1.044 \\
0.194 \\
0.206 \\
0.500\end{array}$ & $\begin{array}{c}0 \\
0.357 \\
26.277 \\
0 \\
0 \\
0 \\
0.174 \\
0\end{array}$ & $\begin{array}{c}1 \\
1 \\
39.585 \\
7.517 \\
6.174 \\
1 \\
1 \\
1\end{array}$ \\
\hline $\begin{array}{l}\text { Other statistics: } \\
\text { Number of songs } \\
\text { Number of releases (albums }+ \text { singles) } \\
\text { Number of singles } \\
\text { Proportion of singles to releases } \\
\text { Year }\end{array}$ & $\begin{array}{l}\text { Firm } \\
\text { Firm } \\
\text { Firm } \\
\text { Firm } \\
\text { Firm }\end{array}$ & $\begin{array}{c}35.010 \\
3.905 \\
1.184 \\
0.264 \\
2005.102\end{array}$ & $\begin{array}{c}59.582 \\
6.099 \\
3.151 \\
0.382 \\
5.570\end{array}$ & $\begin{array}{c}1 \\
1 \\
0 \\
0 \\
1995\end{array}$ & $\begin{array}{c}1838 \\
237 \\
142 \\
1 \\
2015\end{array}$ \\
\hline $\begin{array}{l}\text { Number of firm-year observations } \\
\text { Number of unique firms } \\
\text { Number of unique artists } \\
\text { Number of unique releases } \\
\text { Number of unique songs }\end{array}$ & & $\begin{array}{r}2 \\
9 \\
4 \\
11 \\
1,0\end{array}$ & $\begin{array}{l}, 317 \\
667 \\
, 422 \\
4,488 \\
6,390\end{array}$ & & \\
\hline
\end{tabular}


Table 4: (Variation generation stage) Does producing singles facilitate experimenting with more new artists?

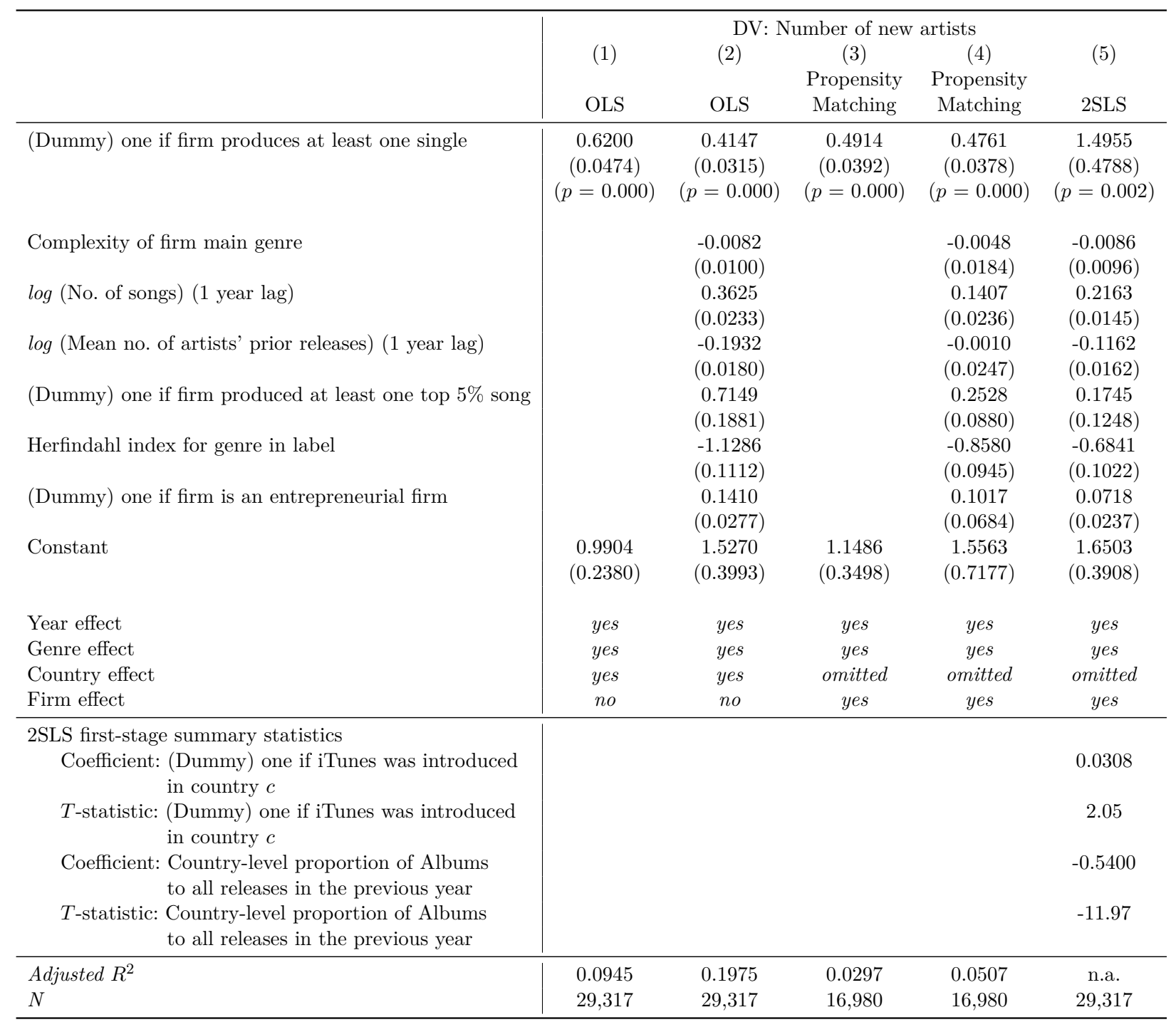

Note: Standard errors are clustered at the firm level. The Sargan's $J$-statistic $\left(\chi^{2}(1)\right)$ is $1.332(p=0.2484)$, alleviating concerns about an over-identification problem. 
Table 5: (Selection and retention stages) Does producing singles increase the number of talented artists who were missed after their first release?

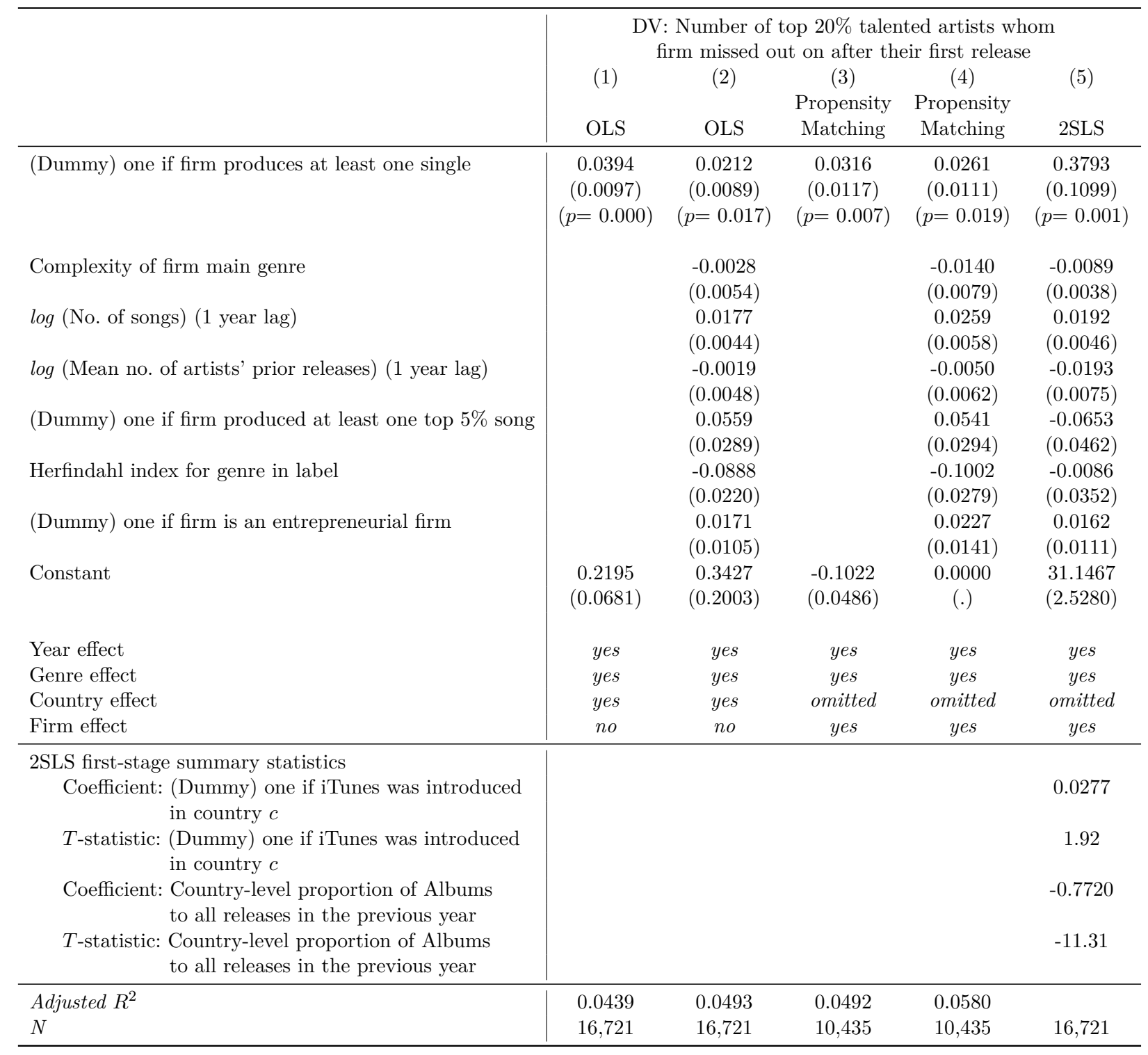

Note: Standard errors are clustered at the firm level. The Sargan's $J$-statistic $\left(\chi^{2}(1)\right)$ is $3.120(p=0.0773)$, alleviating concerns about an over-identification problem. 
Table 6: (Selection and retention stages) Does producing singles increase the performance target of new artists' first releases for selection and retention?

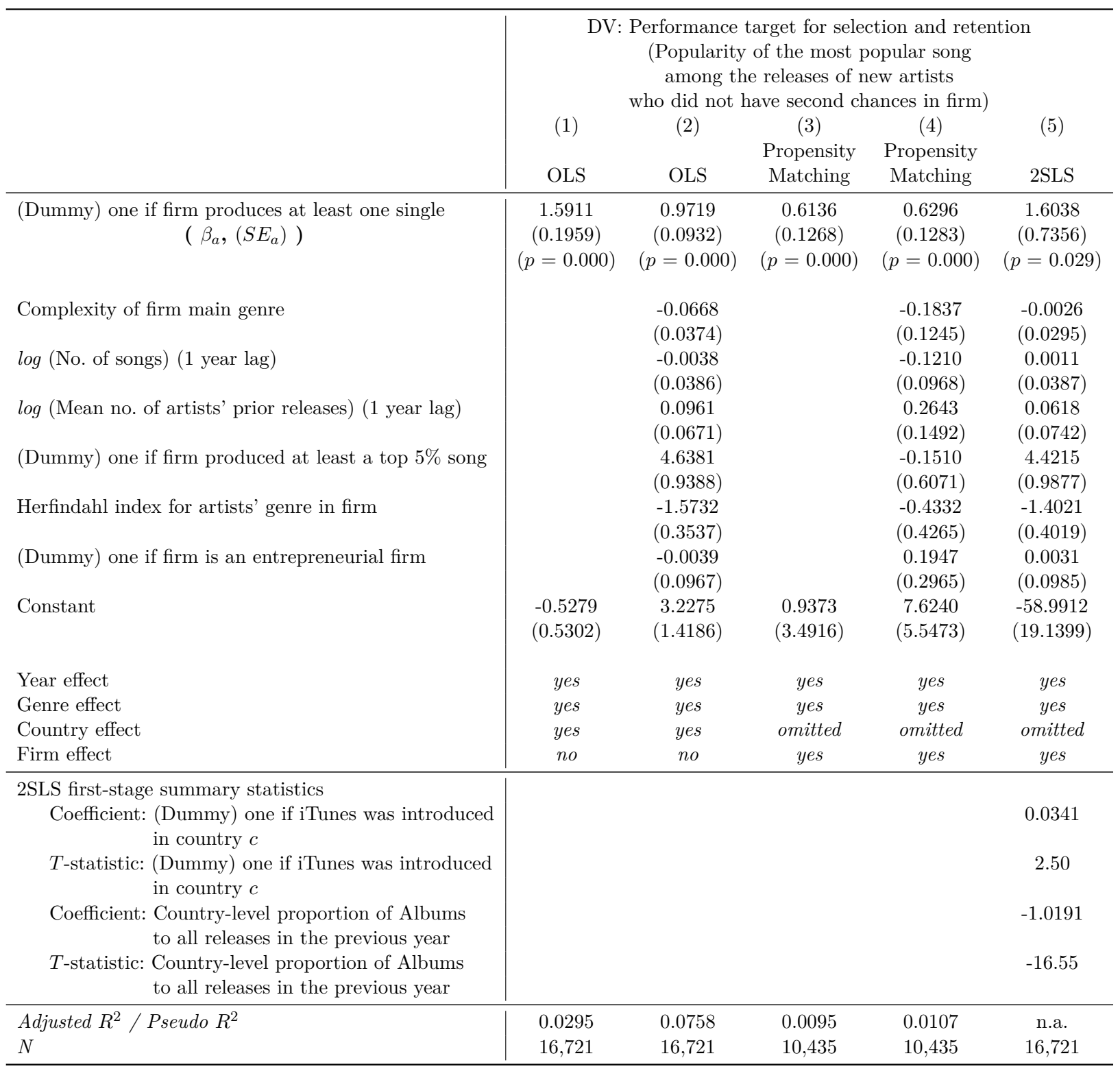

Note: Standard errors are clustered at the firm level. The Sargan's $J$-statistic $\left(\chi^{2}(1)\right)$ is $3.510(p=0.0610)$, alleviating concerns about an over-identification problem. 


\section{Table 7: Sobel test for the mediation (through the performance target)}

Panel A. Testing H2 with the mediator and independent variable

\begin{tabular}{|c|c|c|c|c|}
\hline & $\begin{array}{l}\text { DV: Num } \\
\text { firm mi } \\
\text { (1) } \\
\text { OLS }\end{array}$ & $\begin{array}{l}\text { aber of top } 20 \% \\
\text { issed out on aft } \\
\text { (2) } \\
\text { OLS }\end{array}$ & $\begin{array}{l}\text { talented artist } \\
\text { ter their first re } \\
(3) \\
\text { Propensity } \\
\text { Matching }\end{array}$ & $\begin{array}{l}\text { whom } \\
\text { ease } \\
\quad(4) \\
\text { Propensity } \\
\text { Matching }\end{array}$ \\
\hline $\begin{array}{l}\text { Performance target for selection and retention } \\
\qquad\left(\beta_{b},\left(S E_{b}\right)\right)\end{array}$ & $\begin{array}{c}0.0049 \\
(0.0017) \\
(p=0.004)\end{array}$ & $\begin{array}{c}0.0039 \\
(0.0016) \\
(p=0.017)\end{array}$ & $\begin{array}{c}0.0051 \\
(0.0017) \\
(p=0.003)\end{array}$ & $\begin{array}{c}0.0040 \\
(0.0016) \\
(p=0.014)\end{array}$ \\
\hline (Dummy) one if firm produces at least one single & $\begin{array}{c}0.0316 \\
(0.0093) \\
(p=0.001)\end{array}$ & $\begin{array}{c}0.0174 \\
(0.0090) \\
(p=0.053)\end{array}$ & $\begin{array}{c}0.0239 \\
(0.0114) \\
(p=0.036)\end{array}$ & $\begin{array}{c}0.0220 \\
(0.0111) \\
(p=0.048)\end{array}$ \\
\hline $\begin{array}{l}\text { Percentage explained by the mediation through } \\
\text { the increase in the performance target }\end{array}$ & $\begin{array}{c}\mathbf{1 9 . 8 0 \%} \\
\left(=1-\frac{0.0316}{0.0394}\right)\end{array}$ & $\begin{aligned} & \mathbf{1 7 . 9 2 \%} \\
= & \left.1-\frac{0.0174}{0.0212}\right)\end{aligned}$ & $\begin{aligned} & \mathbf{2 4 . 3 7 \%} \\
(= & \left.1-\frac{0.0239}{0.0316}\right)\end{aligned}$ & $\begin{array}{c}\mathbf{1 5 . 7 1 \%} \\
\left(=1-\frac{0.0220}{0.0261}\right)\end{array}$ \\
\hline $\begin{array}{l}\text { Control variables } \\
\text { Year, Genre, \& Country Effects } \\
\text { Firm effect }\end{array}$ & $\begin{array}{l}\text { no } \\
\text { yes } \\
\text { no }\end{array}$ & $\begin{array}{l}\text { yes } \\
\text { yes } \\
\text { no }\end{array}$ & $\begin{array}{l}\text { no } \\
\text { yes } \\
\text { yes }\end{array}$ & $\begin{array}{l}\text { yes } \\
\text { yes } \\
\text { yes }\end{array}$ \\
\hline $\begin{array}{l}\text { Adjusted } R^{2} \\
N\end{array}$ & $\begin{array}{l}0.0462 \\
29,317\end{array}$ & $\begin{array}{l}0.0508 \\
29,317\end{array}$ & $\begin{array}{l}0.0527 \\
16,980\end{array}$ & $\begin{array}{l}0.0603 \\
16,980\end{array}$ \\
\hline \multicolumn{5}{|c|}{ Panel B. Sobel test statistics } \\
\hline & $\begin{array}{l}\text { (1) } \\
\text { OLS }\end{array}$ & $\begin{array}{l}(2) \\
\text { OLS }\end{array}$ & $\begin{array}{l}\text { (3) } \\
\text { Propensity } \\
\text { Matching }\end{array}$ & $\begin{array}{l}\text { (4) } \\
\text { Propensity } \\
\text { Matching }\end{array}$ \\
\hline $\begin{array}{l}\text { Sobel Test Statistics } \\
\left(\left(\beta_{a} \times \beta_{b}\right) / \sqrt{\left(\beta_{b}^{2} \times S E_{a}^{2}+\beta_{a}^{2} \times S E_{b}^{2}\right)}\right)\end{array}$ & $\begin{array}{c}7.8163 \\
(0.0100) \\
(p=0.000)\end{array}$ & $\begin{array}{c}2.3735 \\
(0.0016) \\
(p=0.018)\end{array}$ & $\begin{array}{c}2.5497 \\
(0.0012) \\
(p=0.011)\end{array}$ & $\begin{array}{c}2.2276 \\
(0.0011) \\
(p=0.026)\end{array}$ \\
\hline
\end{tabular}

Note: Standard errors are clustered at the firm level. 


\section{Table 8: Boundary conditions for Hypothesis 2}

Panel A. Established firms vs. Entrepreneurial firms

\begin{tabular}{|c|c|c|c|c|}
\hline & \multicolumn{2}{|c|}{$\begin{array}{l}\text { DV: No. of omission errors } \\
\text { (Number of top } 20 \% \\
\text { talented artists whom } \\
\text { firm missed out after } \\
\text { their first release) }\end{array}$} & \multicolumn{2}{|c|}{$\begin{array}{l}\text { DV: Perfomance target } \\
\text { (Popularity of the most } \\
\text { song among the releases } \\
\text { of new artists who did } \\
\text { not have second chances } \\
\text { in firm) }\end{array}$} \\
\hline & $\begin{array}{l}\text { Subsample: } \\
\text { Established } \\
\quad \text { firms } \\
\quad(1) \\
\text { Propensity } \\
\text { Matching }\end{array}$ & $\begin{array}{c}\text { Subsample: } \\
\text { Entrepreneurial } \\
\text { firms } \\
(2) \\
\text { Propensity } \\
\text { Matching }\end{array}$ & $\begin{array}{l}\text { Subsample: } \\
\text { Established } \\
\quad \text { firms } \\
\quad(3) \\
\text { Propensity } \\
\text { Matching }\end{array}$ & $\begin{array}{c}\text { Subsample: } \\
\text { Entrepreneurial } \\
\text { firms } \\
(4) \\
\text { Propensity } \\
\text { Matching }\end{array}$ \\
\hline (Dummy) one if firm produces at least one single & $\begin{array}{c}0.0363 \\
(0.0124) \\
(p=0.003)\end{array}$ & $\begin{array}{c}0.0119 \\
(0.0191) \\
(p=0.533)\end{array}$ & $\begin{array}{c}1.4338 \\
(0.1570) \\
(p=0.000)\end{array}$ & $\begin{array}{c}0.6780 \\
(0.0975) \\
(p=0.000)\end{array}$ \\
\hline $\begin{array}{l}\text { Control variables } \\
\text { Year, Genre, \& Country Effects } \\
\text { Firm effect }\end{array}$ & $\begin{array}{l}\text { yes } \\
\text { yes } \\
\text { yes }\end{array}$ & $\begin{array}{l}\text { yes } \\
\text { yes } \\
\text { yes }\end{array}$ & $\begin{array}{l}\text { yes } \\
\text { yes } \\
\text { yes }\end{array}$ & $\begin{array}{l}\text { yes } \\
\text { yes } \\
\text { yes }\end{array}$ \\
\hline $\begin{array}{l}\text { Adjusted } R^{2} \\
N\end{array}$ & $\begin{array}{c}0.0890 \\
5,443\end{array}$ & $\begin{array}{c}0.0443 \\
4,992\end{array}$ & $\begin{array}{c}0.0880 \\
5,443\end{array}$ & $\begin{array}{c}0.0331 \\
4,992\end{array}$ \\
\hline
\end{tabular}

Panel B. Pop genres (Pop, Hip-hop, Rock, Funksoul) vs. Non-pop genres

\begin{tabular}{|c|c|c|c|c|}
\hline & \multicolumn{2}{|c|}{$\begin{array}{l}\text { DV: No. of omission errors } \\
\text { (Number of top } 20 \% \\
\text { talented artists whom } \\
\text { firm missed out after } \\
\text { their first release) }\end{array}$} & \multicolumn{2}{|c|}{$\begin{array}{l}\text { DV: Perfomance target } \\
\text { (Popularity of the most } \\
\text { song among the releases } \\
\text { of new artists who did } \\
\text { not have second chances } \\
\text { in firm) }\end{array}$} \\
\hline & $\begin{array}{l}\text { Subsample: } \\
\text { Pop } \\
\text { genres } \\
\quad(1) \\
\text { Propensity } \\
\text { Matching }\end{array}$ & $\begin{array}{l}\text { Subsample: } \\
\text { Non-pop } \\
\text { genres } \\
\quad(2) \\
\text { Propensity } \\
\text { Matching }\end{array}$ & $\begin{array}{l}\text { Subsample: } \\
\text { Pop } \\
\text { genres } \\
\quad(3) \\
\text { Propensity } \\
\text { Matching }\end{array}$ & $\begin{array}{l}\text { Subsample: } \\
\text { Non-pop } \\
\text { genres } \\
(4) \\
\text { Propensity } \\
\text { Matching }\end{array}$ \\
\hline (Dummy) one if firm produces at least one single & $\begin{array}{c}0.0362 \\
(0.0191) \\
(p=0.059)\end{array}$ & $\begin{array}{c}0.0229 \\
(0.0140) \\
(p=0.102)\end{array}$ & $\begin{array}{c}1.3721 \\
(0.1844) \\
(p=0.000)\end{array}$ & $\begin{array}{c}1.0108 \\
(0.1242) \\
(p=0.000)\end{array}$ \\
\hline Control variables & yes & yes & yes & yes \\
\hline Year, Genre, \& Country Effects & yes & yes & yes & yes \\
\hline Firm effect & yes & yes & yes & yes \\
\hline $\begin{array}{l}\text { Adjusted } R^{2} \\
N\end{array}$ & $\begin{array}{c}0.0719 \\
3,443\end{array}$ & $\begin{array}{c}0.0582 \\
6,992\end{array}$ & $\begin{array}{c}0.0672 \\
3,443\end{array}$ & $\begin{array}{c}0.0924 \\
6,992\end{array}$ \\
\hline
\end{tabular}

Note: Standard errors are clustered at the firm level. 


\section{Table 9: Difference in average talent level of artists between singles and albums}

\begin{tabular}{|c|c|c|c|c|c|c|}
\hline & $\begin{array}{l}\text { DV: } \\
\text { DV } \\
\text { (1) } \\
\text { Propensity } \\
\text { Matching } \\
\text { OLS }\end{array}$ & $\begin{array}{l}\text { mple: Firm-le } \\
\text { rerage talent } \\
\text { new artists } \\
(2) \\
\text { Propensity } \\
\text { Matching } \\
\text { OLS }\end{array}$ & $\begin{array}{l}\text { el } \\
\text { (3) } \\
\text { 2SLS }\end{array}$ & $\begin{array}{c}\text { Sa } \\
\\
\text { D } \\
\text { (4) } \\
\text { Propensity } \\
\text { Matching } \\
\text { OLS }\end{array}$ & $\begin{array}{l}\text { ple: Artist-l } \\
\text { Talent leve } \\
\text { artist } j \\
\quad(5) \\
\text { Propensity } \\
\text { Matching } \\
\text { OLS }\end{array}$ & 2SLS \\
\hline (Dummy) one if firm produces at least one single & $\begin{array}{c}0.0654 \\
(0.2478) \\
(p=0.792)\end{array}$ & $\begin{array}{c}0.0905 \\
(0.2480) \\
(p=0.715)\end{array}$ & $\begin{array}{c}2.5758 \\
(1.7558) \\
(p=0.142)\end{array}$ & & & \\
\hline $\begin{array}{l}\text { (Dummy) one if the first release of artist } j \\
\text { is produced by a single }\end{array}$ & & & & $\begin{array}{c}-0.0058 \\
(0.0616) \\
(p=0.925)\end{array}$ & $\begin{array}{c}-0.0133 \\
(0.0619) \\
(p=0.831)\end{array}$ & $\begin{array}{c}1.4064 \\
(3.3042) \\
(p=0.670)\end{array}$ \\
\hline Complexity of firm main genre & & $\begin{array}{l}-0.1997 \\
(0.1337)\end{array}$ & $\begin{array}{l}-0.1306 \\
(0.0593)\end{array}$ & & $\begin{array}{l}-0.0259 \\
(0.0322)\end{array}$ & $\begin{array}{l}-0.3071 \\
(0.0716)\end{array}$ \\
\hline $\log$ (No. of songs) (1 year lag) & & $\begin{array}{l}-0.2695 \\
(0.1139)\end{array}$ & $\begin{array}{c}0.1607 \\
(0.0467)\end{array}$ & & $\begin{array}{c}0.0368 \\
(0.0177)\end{array}$ & $\begin{array}{l}-0.1776 \\
(0.1021)\end{array}$ \\
\hline $\log$ (Mean no. of artists' prior releases) (1 year lag) & & $\begin{array}{c}0.2028 \\
(0.1190)\end{array}$ & $\begin{array}{l}-0.3727 \\
(0.0787)\end{array}$ & & $\begin{array}{l}-0.0853 \\
(0.0317)\end{array}$ & $\begin{array}{l}-0.1450 \\
(0.1082)\end{array}$ \\
\hline (Dummy) one if firm produced at least a top $5 \%$ song & & $\begin{array}{c}0.8245 \\
(0.4289)\end{array}$ & $\begin{array}{c}0.4996 \\
(0.6035)\end{array}$ & & $\begin{array}{c}0.2166 \\
(0.0828)\end{array}$ & $\begin{array}{c}0.3283 \\
(0.3355)\end{array}$ \\
\hline Herfindahl index for artists' genre in firm & & $\begin{array}{l}-1.2511 \\
(0.4811)\end{array}$ & $\begin{array}{l}-1.2085 \\
(0.5029)\end{array}$ & & $\begin{array}{l}-0.0904 \\
(0.1029)\end{array}$ & $\begin{array}{l}-1.4681 \\
(0.3457)\end{array}$ \\
\hline (Dummy) one if firm is an entrepreneurial firm & & $\begin{array}{l}-0.0049 \\
(0.3391)\end{array}$ & $\begin{array}{c}0.2372 \\
(0.1324)\end{array}$ & & $\begin{array}{c}0.0376 \\
(0.0568)\end{array}$ & $\begin{array}{c}0.7410 \\
(0.2521)\end{array}$ \\
\hline Constant & $\begin{array}{l}12.9682 \\
(3.8657)\end{array}$ & $\begin{array}{l}21.2401 \\
(6.0759)\end{array}$ & $\begin{array}{l}11.1143 \\
(2.6811)\end{array}$ & $\begin{array}{l}-0.8624 \\
(0.1899)\end{array}$ & $\begin{array}{c}0.0239 \\
(1.1022)\end{array}$ & $\begin{array}{l}1220.1770 \\
(62.8332)\end{array}$ \\
\hline Year effect & yes & yes & yes & yes & yes & yes \\
\hline Genre effect & yes & yes & yes & yes & yes & yes \\
\hline Country effect & yes & yes & omitted & yes & yes & omitted \\
\hline Firm effect & no & no & yes & no & no & yes \\
\hline $\begin{array}{l}\text { Adjusted } R^{2} \\
N\end{array}$ & 16,980 & 16,980 & 29,317 & $\begin{array}{l}0.2963 \\
11,751\end{array}$ & $\begin{array}{l}0.2972 \\
11,751\end{array}$ & $\begin{array}{c}\text { n.a. } \\
42,422\end{array}$ \\
\hline
\end{tabular}

Note: Standard errors are clustered at the firm level. 
Table 10: Does producing singles increase commission errors in the selection and retention stages (giving second chances to unpromising options)?

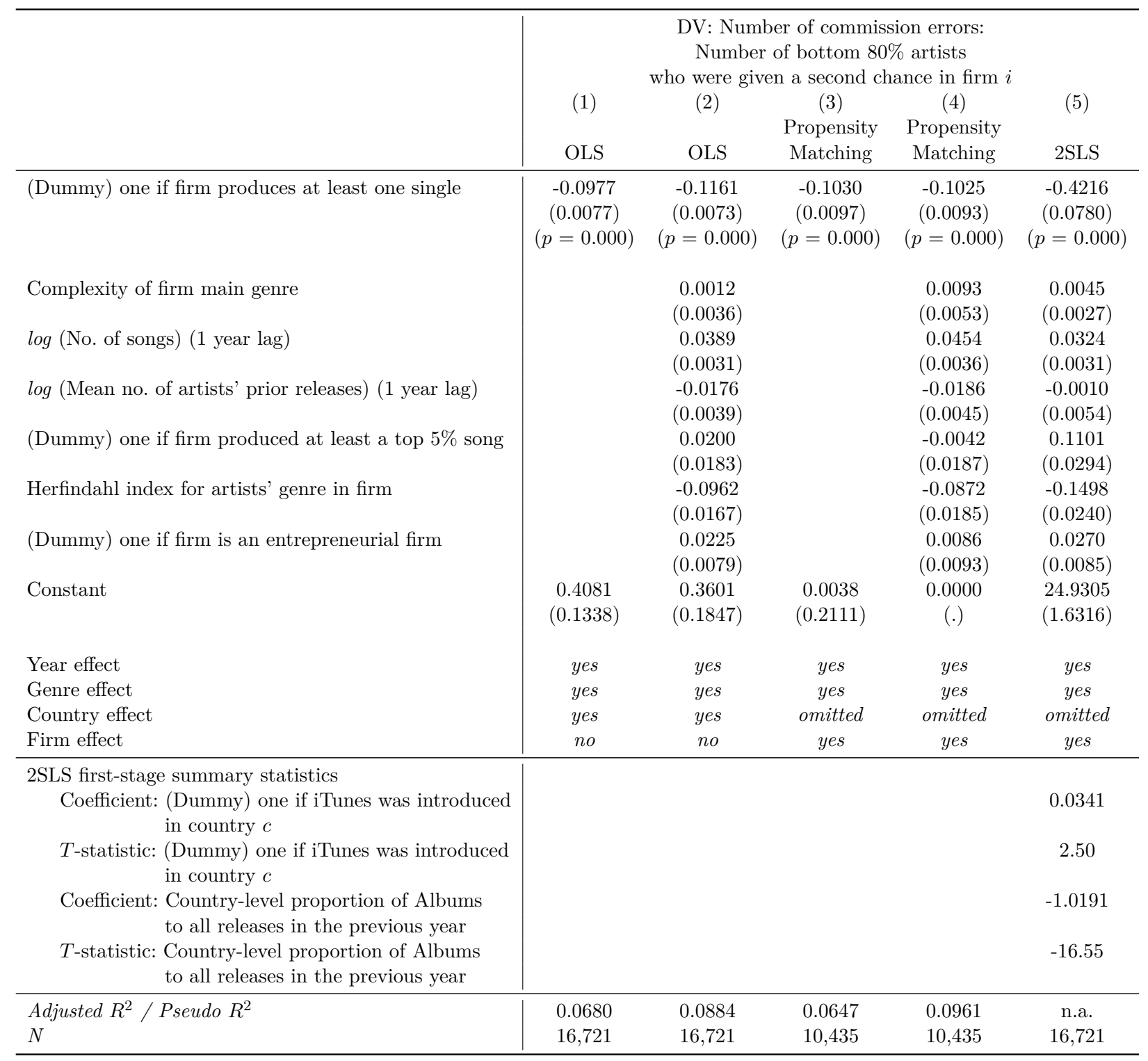

Note: Standard errors are clustered at the firm level. The Sargan's $J$-statistic $\left(\chi^{2}(1)\right)$ is $3.510(p=0.0610)$, alleviating concerns about an over-identification problem. 
Table 11: Commission errors by person (solo) vs. group

Panel A. Subsample - Person (Solo)

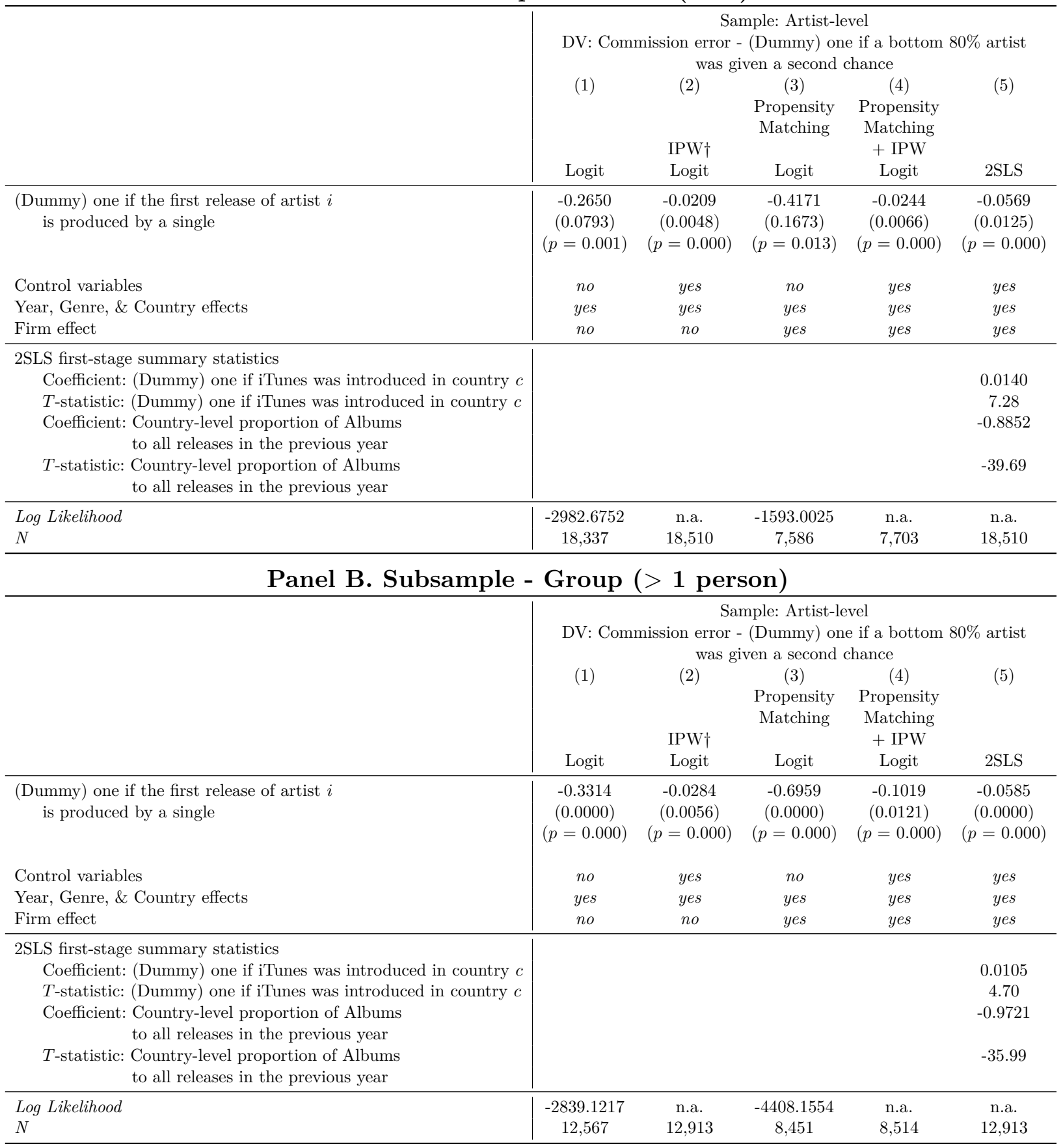

Note: Standard errors are clustered at the firm level. $\dagger$ We estimate the average treatment effect by using an inverseprobability weighting (IPW). An inverse probability weighting involves two steps. First, for each $t$, we estimate a logit of $s_{i t}$ (i.e., single production) on $X_{i t}$. Let $p_{i t}$ be the fitted probabilities. In the second step, the objective function for $(i, t)$ is weighted by $1 / p_{i t}$ (Angrist and Pischke, 2008). For this analysis, we use the teffects ipw routine in Stata. 


\section{Appendix A. Description on databases}

\section{Musicbrainz database}

MusicBrainz is a project that aims to create an open content music database. MusicBrainz was founded as a database for software applications to look up audio CD (compact disc) information on the Internet. MusicBrainz has expanded its goals to reach beyond a compact disc metadata storehouse to become a structured open online database for music. The MusicBrainz Database covers information about artists, release groups, releases, recordings, works, and labels, as well as the many relationships between them. The database also contains a history of all the changes that the MusicBrainz community has made to the data (Musicbrainz, 2016). The first strength of Musicbrainz database is its large coverage. The second strength is that it has information on labels. On the contrary, Spotify APIs do not offer the label information on their databases (Highfield, 2007).

\section{Spotify Echo Nest API}

The Echo Nest was a music intelligence and data platform for developers and media companies. Its creators intended it to perform music identification, recommendation, playlist creation, audio fingerprinting, and analysis for consumers and developers. On March 6, 2014 Spotify announced that they had acquired The Echo Nest. Spotify shut down the Echo Nest API on May 31, 2016 and developers was encouraged to use the Spotify Echo Nest API which integrate the original Echo Nest API instead. The Echo Nest offered their database of data about 30 million songs aggregated from web crawling, data mining, and digital signal processing techniques. The strength is from using multiple sources such as web crawling, data mining, and digital signal processing, they measure popularity of artists. This is derived from many sources, including play counts, mentions on the web, mentions in music blogs, music reviews, Twitter, Facebook, and the catalogue of streaming applications.

The Echo Nest offered two popularity measures: familiarity and hotness. We choose familiarity as our popularity measure because it measures the life-time popularity for artists. Specifically, familiarity measures how well known in artist is. One can understand familiarity as the likelihood that any person selected at random will have heard of the artist. Beatles have a familiarity close to 1, while a band like 'Hot Rod Shopping Cart' has a familiarity close to zero. On the other hand, hotness corresponds to how much buzz the artist is getting right now. Figure A1 shows the results. The $\mathrm{x}$-axis is familiarity, and the $\mathrm{y}$-axis is hotness. Clearly there is a correlation between hotness and familiarity. Familiar artists tend to be hotter than non-familiar artists. At the top right are the Billboard chart toppers like Kanye West and Taylor Swift, while at the bottom left are artists that you have never heard of like Mystery Fluid. This plot shows artists as well as the popular artists that are cooling off. Outliers to the left and above the main diagonal are the rising stars (Music Machinery, 2009).

The last strength of the Echo Nest is that it offers a ID matching scheme for many different databases. The Echo Nest eliminated some of the trouble with mapping IDs with Project Rosetta Stone. Rosetta Stone is to allow a researcher to use any music id from any music API with the Echo Nest web services. I use this matching scheme to merge multiple databases. 
Figure A1. Two popularity measures and their relation

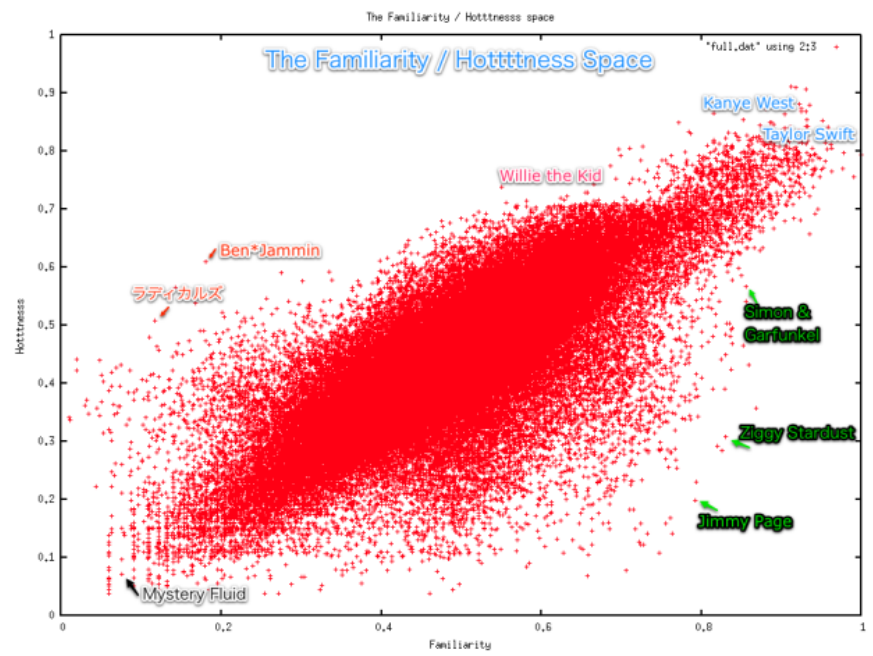

Source: Music Machinery (https://musicmachinery.com/2009/12/09/a-rising-star-or/).

\section{Spotify Web API}

In June 2014, Spotify released a new Web API that allowed third-party developers to integrate Spotify content in their own applications (Spotify, 2014). The Spotify Web API is a web service that can be accessed by programs through the Hypertext Transfer Protocol. It returns data about albums, artists, tracks, playlists and other Spotify resources in JSON format. We use song popularity data. The popularity of a track is based on (1) the total number of plays compared to other tracks and (2) how recent those plays are. We extract song popularity data with the International Standard Recording Code code and match with Musicbrainz and Echo Nest data.

\section{References}

The Echo Nest Lab, 2009, The Map of Music Styles (http://static.echonest.com/playlist/moms/) Retreived on 2016-09-18.

Highfield, Ashley. 2007. Keynote speech given at IEA Future Of Broadcasting Conference (http://www.bbc.co.uk/pressoffice/speeches/stories/highfield_iea.shtml), BBC Press Office. Retrieved on 2016-09-18.

Musicbrainz, 2016, Musicbrainz Database (https://musicbrainz.org/doc/MusicBrainz Database\#Core_data). Retreived on 2016-09-18.

Music Machinery, 2009, Hottt or Nottt? (https://musicmachinery.com/2009/12/09/ a-rising-star-or/) Retreived on 2016-09-18.

Spotify, 2014, Say Hello to Our New Web API. Spotify Developer Website (https://developer.spotify.com/news-stories/2014/06/17/say-hello-new-web-api/). Retreived on 2016-09-18. 
Appendix B. History of staggered entries of iTunes into 29 sample countries

\begin{tabular}{|c|c|c|c|c|}
\hline & Country & Entry time & $\begin{array}{l}\text { Ranking by no. of } \\
\text { firms in Musicbrainz }\end{array}$ & $\begin{array}{l}\text { No of firms } \\
\text { in Musicbrainz }\end{array}$ \\
\hline 1 & United States & 28-Apr-03 & 1 & 16,916 \\
\hline 2 & United Kingdom & 15-Jun-04 & 2 & 8,914 \\
\hline 3 & France & 15-Jun-04 & 5 & 2,974 \\
\hline 4 & Germany & 15-Jun-04 & 3 & 5,398 \\
\hline 5 & Austria & 26-Oct-04 & 23 & 355 \\
\hline 6 & Belgium & 26-Oct-04 & 14 & 729 \\
\hline 7 & Finland & 26-Oct-04 & 10 & 1,329 \\
\hline 8 & Greece & 26-Oct-04 & 21 & 366 \\
\hline 9 & Italy & 26-Oct-04 & 6 & 1,919 \\
\hline 10 & Netherlands & 26-Oct-04 & 9 & 1,490 \\
\hline 11 & Portugal & 26-Oct-04 & 26 & 258 \\
\hline 12 & Spain & 26-Oct-04 & 11 & 1,249 \\
\hline 13 & Canada & 3-Dec-04 & 8 & 1,638 \\
\hline 14 & Ireland & 6-Jan-05 & 28 & 234 \\
\hline 15 & Sweden & 10-May-05 & 7 & 1,660 \\
\hline 16 & Norway & 10-May-05 & 16 & 546 \\
\hline 17 & Switzerland & 10-May-05 & 17 & 528 \\
\hline 18 & Denmark & 10-May-05 & 19 & 443 \\
\hline 19 & Japan & 4-Aug-05 & 4 & 3,676 \\
\hline 20 & Australia & 25-Oct-05 & 12 & 1,152 \\
\hline 21 & New Zealand & 6-Dec-05 & 24 & 307 \\
\hline 22 & Mexico & 4-Aug-09 & 29 & 217 \\
\hline 23 & Czech Republic & 29-Sep-11 & 25 & 288 \\
\hline 24 & Estonia & 29-Sep-11 & 22 & 359 \\
\hline 25 & Poland & 29-Sep-11 & 15 & 573 \\
\hline 26 & Argentina & 13-Dec-11 & 27 & 235 \\
\hline 27 & Brazil & 13-Dec-11 & 18 & 467 \\
\hline 28 & Russia & 4-Dec-12 & 13 & 817 \\
\hline \multirow[t]{2}{*}{29} & Turkey & 4-Dec-12 & 20 & 375 \\
\hline & Total & - & - & 55,412 \\
\hline
\end{tabular}

Note: We exclude countries which have fewer than 200 unique music production firms in the Musicbrainz database. The final sample consists of 29,317 firm-years associated with 9,667 firms. 


\section{Appendix C. Measure of genre complexity}

A rugged landscape illustrates the basic challenge posed by complex problems (Levinthal, 1997, Baumann and Siggelkow, 2013). Each location on the landscape represents a combination of activities, and the height of the location represents the performance of the combination. An important source of complexity is the interdependence among activities, which results in a rugged landscape with many local peaks and valleys. Bounded rational firms will have difficulty experimenting with new options and will tend to stick to local peaks. This landscape metaphor tells us that, as complexity increases, firms will more likely be scattered across different local peaks. Prior work measures heterogeneity with product subspace as a proxy for product space complexity (e.g., Barroso and Giarratana, 2013, Piazzai and Wijnberg, 2019).

Specifically, we follow Piazzai and Wijnberg's approach (2019) to measure the complexity of the music genre. We measure complexity for each music genre during each year of the sample period by using the Discogs and AcousticBrainz databases. First, genre information on each release and music genre come from the Discogs database. The Discogs database has 14 music genres: Blues, Brass and Military, Children, Classical, Electronic, Folk, Funk and Soul, Hip Hop, Jazz, Latin, Pop, Reggae, Rock, and Stage and Screen. We exclude two music genres-Brass and Military, and Stage and Screen - because these two genres are not considered commercial music. Second, we use the musical attribute data from AcousticBrainz. AcousticBrainz provides musical attributes and fingerprints of songs including danceability, acousticness, energy, valence (happiness), speechness, mode (major or minor), track length, primary key, scale and frequency of the primary key, scale of the most frequent chord progression key, average number of beats per minutes, and beat count. By using these attributes, we calculate the centroid of each genre during each year of observation and compute the Mahalanobis distance of each product in the genre-year from this centroid. We use the mean distance as our moderator because it increases with the degree of heterogeneity in product attributes. 


\section{Appendix D. Kernel density distribution of the probability of producing at least one single}

\section{Panel A. Before matching}

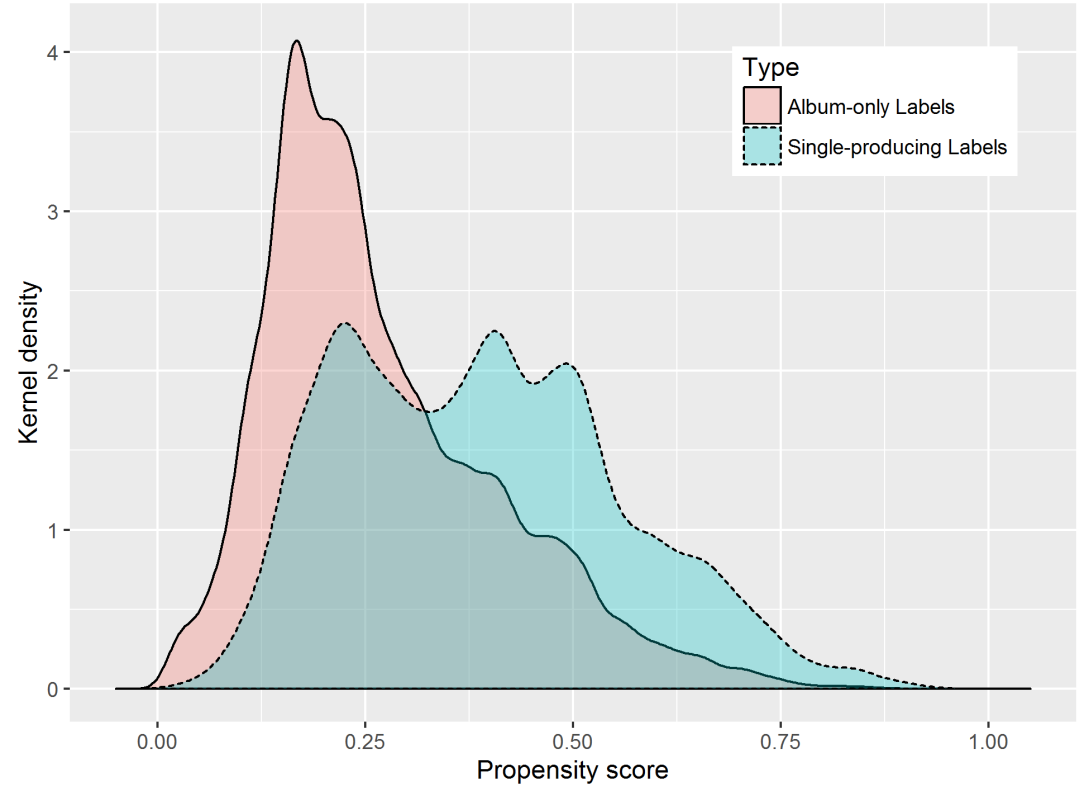

Panel B. After matching

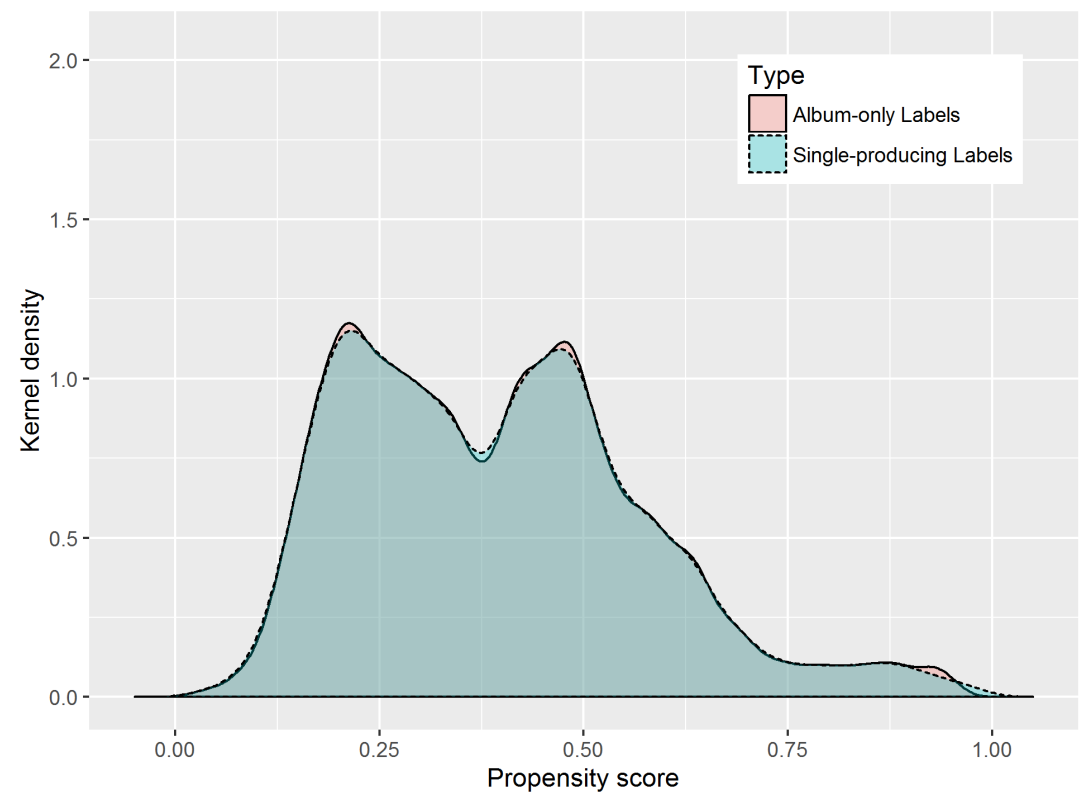

Note: Figure 5 shows why matching may matter. In Panel A, the distributions of the propensity scores before matching are quite different from the treatment group and control group $(n=29,317)$. Panel B demonstrates that the distributions of the propensity scores after matching $(n=16,980)$. Visually there exists a tighter fit between the two groups after matching. We trim 12,337 observations which are off the common support of the propensity distribution to get the matched sample. 


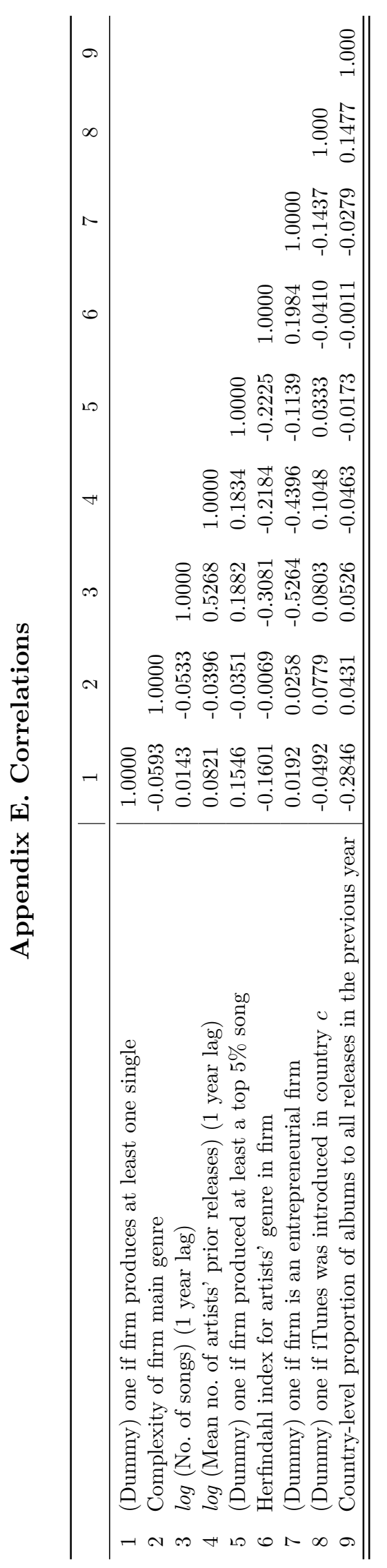




\section{Appendix F. (Subsample) Analysis on firms that discovered at least one top 20\% popular artist)}

Panel A. Missing out on top 20\% talented artists (Firm-level)

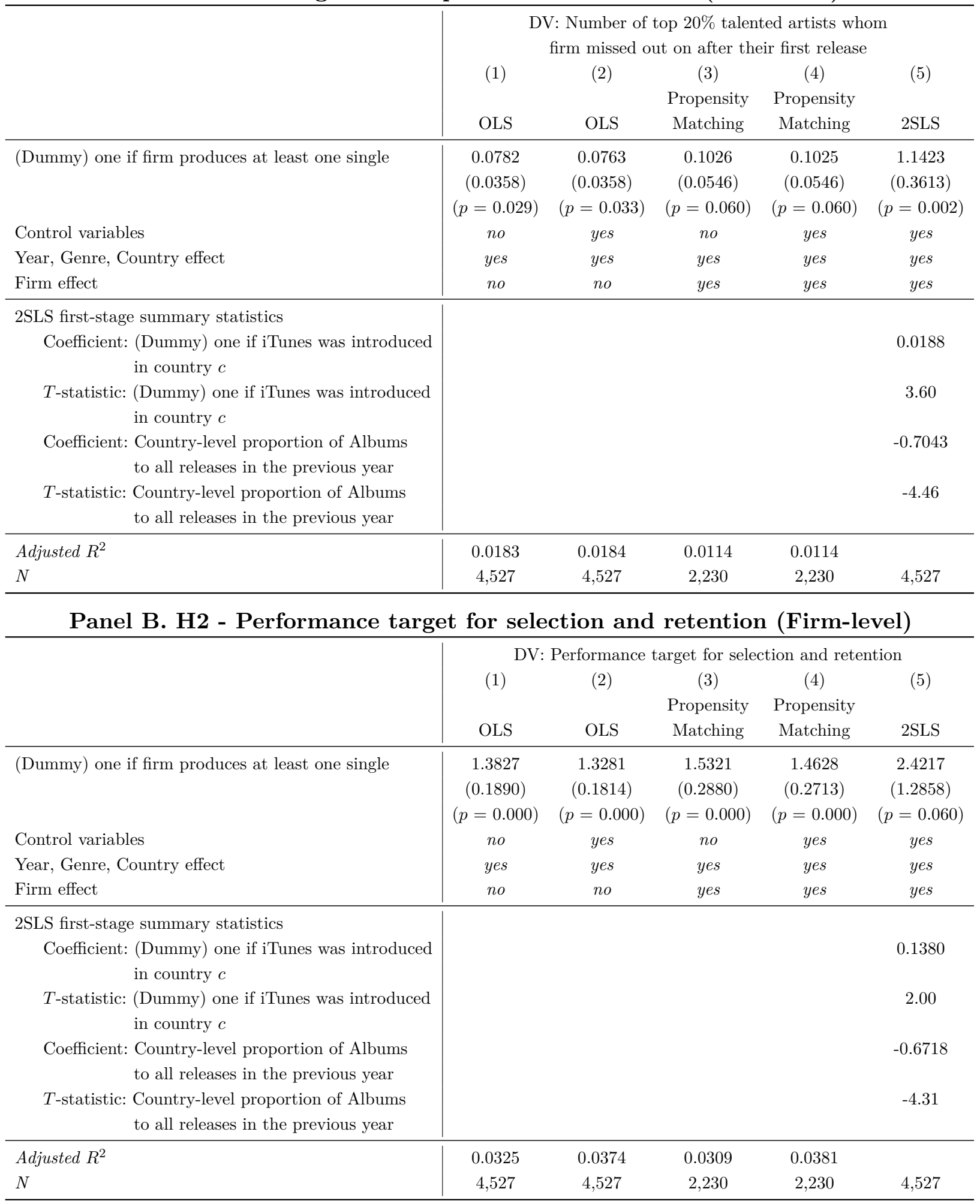

Note: Standard errors are clustered at the firm level. 


\section{Appendix G. An alternative measure for single production - Average number of songs per release in firm}

Panel A. H1 - DV: Number of new artists (Firm-level)

\begin{tabular}{|c|c|c|c|c|c|}
\hline & \multicolumn{5}{|c|}{ DV: Number of new artists } \\
\hline & (1) & $(2)$ & $(3)$ & $(4)$ & $(5)$ \\
\hline & & & Propensity & Propensity & \\
\hline & OLS & OLS & Matching & Matching & $2 \mathrm{SLS}$ \\
\hline \multirow{3}{*}{$\begin{array}{l}\text { Average number of songs per release } \\
\text { (firm-level) }\end{array}$} & -0.0172 & -0.0346 & -0.0309 & -0.0339 & -0.1784 \\
\hline & $(0.0044)$ & $(0.0035)$ & $(0.0060)$ & $(0.0058)$ & $(0.0541)$ \\
\hline & $(p=0.000)$ & $(p=0.000)$ & $(p=0.000)$ & $(p=0.000)$ & $(p=0.001)$ \\
\hline \multirow{3}{*}{$\begin{array}{l}\text { Control variables } \\
\text { Year, Genre, \& Country effects } \\
\text { Firm effect }\end{array}$} & no & yes & no & yes & yes \\
\hline & yes & yes & yes & yes & yes \\
\hline & no & no & yes & yes & yes \\
\hline \multirow{2}{*}{$\begin{array}{l}\text { Adjusted } R^{2} \\
N\end{array}$} & 0.0945 & 0.1975 & 0.0219 & 0.0454 & n.a. \\
\hline & 29,317 & 29,317 & 16,980 & 16,980 & 29,317 \\
\hline
\end{tabular}

Panel B. H2 - Missing out on top 20\% talented artists (Firm-level)

\begin{tabular}{|c|c|c|c|c|c|}
\hline & $\begin{array}{l}\text { whe } \\
\text { OLS }\end{array}$ & $\begin{array}{l}\text { DV: Number } \\
\text { m firm misse } \\
(2) \\
\text { OLS }\end{array}$ & $\begin{array}{l}\text { of top } 20 \% \text { t } \\
\text { out on after } \\
\quad(3) \\
\text { Propensity } \\
\text { Matching }\end{array}$ & $\begin{array}{l}\text { lented artists } \\
\text { their first rel } \\
\text { (4) } \\
\text { Propensity } \\
\text { Matching }\end{array}$ & $\begin{array}{l}\text { ase } \\
\quad \text { 2SLS }\end{array}$ \\
\hline $\begin{array}{l}\text { Average number of songs per release } \\
\text { (firm-level) }\end{array}$ & $\begin{array}{c}-0.0061 \\
(0.0020) \\
(p=0.000)\end{array}$ & $\begin{array}{c}-0.0091 \\
(0.0019) \\
(p=0.000)\end{array}$ & $\begin{array}{c}-0.0079 \\
(0.0045) \\
(p=0.000)\end{array}$ & $\begin{array}{c}-0.0091 \\
(0.0044) \\
(p=0.000)\end{array}$ & $\begin{array}{c}-0.0796 \\
(0.0316) \\
(p=0.001)\end{array}$ \\
\hline $\begin{array}{l}\text { Control variables } \\
\text { Year, Genre, \& Country effects } \\
\text { Firm effect }\end{array}$ & $\begin{array}{l}\text { no } \\
\text { yes } \\
\text { no }\end{array}$ & $\begin{array}{l}\text { yes } \\
\text { yes } \\
\text { no }\end{array}$ & $\begin{array}{l}\text { no } \\
\text { yes } \\
\text { yes }\end{array}$ & $\begin{array}{l}\text { yes } \\
\text { yes } \\
\text { yes }\end{array}$ & $\begin{array}{l}\text { yes } \\
\text { yes } \\
\text { yes }\end{array}$ \\
\hline $\begin{array}{l}\text { Adjusted } R^{2} \\
N\end{array}$ & $\begin{array}{l}0.0945 \\
16,721\end{array}$ & $\begin{array}{l}0.1975 \\
16,721\end{array}$ & $\begin{array}{l}0.0219 \\
10,435\end{array}$ & $\begin{array}{l}0.0454 \\
10,435\end{array}$ & $\begin{array}{l}\text { n.a. } \\
16,721\end{array}$ \\
\hline
\end{tabular}

Panel C. H2 (Mechanism) - Performance target for selection and retention (Firm-level)

\begin{tabular}{|c|c|c|c|c|c|}
\hline & \multicolumn{5}{|c|}{ DV: Performance target for selection and retention } \\
\hline & (1) & (2) & (3) & (4) & (5) \\
\hline & OLS & OLS & $\begin{array}{l}\text { Propensity } \\
\text { Matching }\end{array}$ & $\begin{array}{l}\text { Propensity } \\
\text { Matching }\end{array}$ & 2SLS \\
\hline $\begin{array}{l}\text { Average number of songs per release } \\
\text { (firm-level) }\end{array}$ & $\begin{array}{c}-0.0799 \\
(0.0135) \\
(p=0.000)\end{array}$ & $\begin{array}{c}-0.0817 \\
(0.0120) \\
(p=0.000)\end{array}$ & $\begin{array}{c}-0.1407 \\
(0.0373) \\
(p=0.000)\end{array}$ & $\begin{array}{c}-0.1437 \\
(0.0370) \\
(p=0.000)\end{array}$ & $\begin{array}{c}-0.1871 \\
(0.0921) \\
(p=0.042)\end{array}$ \\
\hline Control variables & no & yes & no & yes & yes \\
\hline Year, Genre, \& Country effects & yes & yes & yes & yes & yes \\
\hline Firm effect & no & no & yes & yes & yes \\
\hline Adjusted $R^{2}$ & 0.0945 & 0.1975 & 0.0219 & 0.0454 & n.a. \\
\hline$N$ & 16,721 & 16,721 & 10,435 & 10,435 & 16,721 \\
\hline
\end{tabular}

Note: Standard errors are clustered at the firm level. 
Appendix H. Other Robustness checks - Alternative measures and cutoffs

Panel A. (Hypothesis 1) An alternative measure for single production: proportion of singles to all releases in firm

\begin{tabular}{|c|c|c|c|c|}
\hline & $\begin{array}{c}\text { DV: Numbe } \\
\text { (1) } \\
\text { OLS }\end{array}$ & $\begin{array}{l}\text { f new artists } \\
(2) \\
\text { 2SLS }\end{array}$ & \multicolumn{2}{|c|}{$\begin{array}{l}\text { DV: Talent level of the most } \\
\text { talented new artist in firm }\end{array}$} \\
\hline Proportion of singles to all releases & $\begin{array}{c}0.4641 \\
(0.0441) \\
(p=0.000)\end{array}$ & $\begin{array}{c}1.7207 \\
(0.3966) \\
(p=0.000)\end{array}$ & $\begin{array}{c}1.1941 \\
(0.2162) \\
(p=0.000)\end{array}$ & $\begin{array}{c}5.2083 \\
(2.3139) \\
(p=0.024)\end{array}$ \\
\hline Control variables & yes & yes & yes & yes \\
\hline Constant & yes & yes & yes & yes \\
\hline Year effect & yes & yes & yes & yes \\
\hline Genre effect & yes & yes & yes & yes \\
\hline Country effect & yes & omitted & yes & omitted \\
\hline Firm effect & no & yes & no & yes \\
\hline $\begin{array}{l}\text { Adjusted } R^{2} \\
N\end{array}$ & $\begin{array}{l}0.2030 \\
29,317\end{array}$ & $\begin{array}{c}\text { n.a. } \\
29,317\end{array}$ & $\begin{array}{l}0.1676 \\
29,317\end{array}$ & $\begin{array}{c}\text { n.a. } \\
29,317\end{array}$ \\
\hline
\end{tabular}

Panel B. (Hypothesis 2) Different cutoffs for talented artists

\begin{tabular}{l|cccc}
\hline & Top 20\% & Top $15 \%$ & Top $10 \%$ & Top $5 \%$ \\
& $(1)$ & $(2)$ & $(3)$ & $(4)$ \\
& Matched & Matched & Matched & Matched \\
& Sample & Sample & Sample & Sample \\
Logit & Logit & Logit & Logit \\
& (Odds ratio) & (Odds ratio) & (Odds ratio) & (Odds ratio) \\
\hline (Dummy) one if the first release of & 0.8569 & 0.9095 & 0.8091 & 0.7465 \\
artist $j$ is produced by a single & $(0.2065)$ & $(0.2609)$ & $(0.3125)$ & $(0.4444)$ \\
& $(p=0.000)$ & $(p=0.000)$ & $(p=0.010)$ & $(p=0.093)$ \\
Control variables & & & & \\
Constant & yes & yes & yes & yes \\
Year effect & yes & yes & yes & yes \\
Genre effect & yes & yes & yes & yes \\
Country effect & yes & yes & yes & yes \\
\hline Adjusted $R^{2}$ & yes & yes & yes & yes \\
$N$ & 0.0773 & 0.0714 & 0.0860 & 0.1057 \\
\hline
\end{tabular}

Note: Standard errors are clustered at the firm level. 